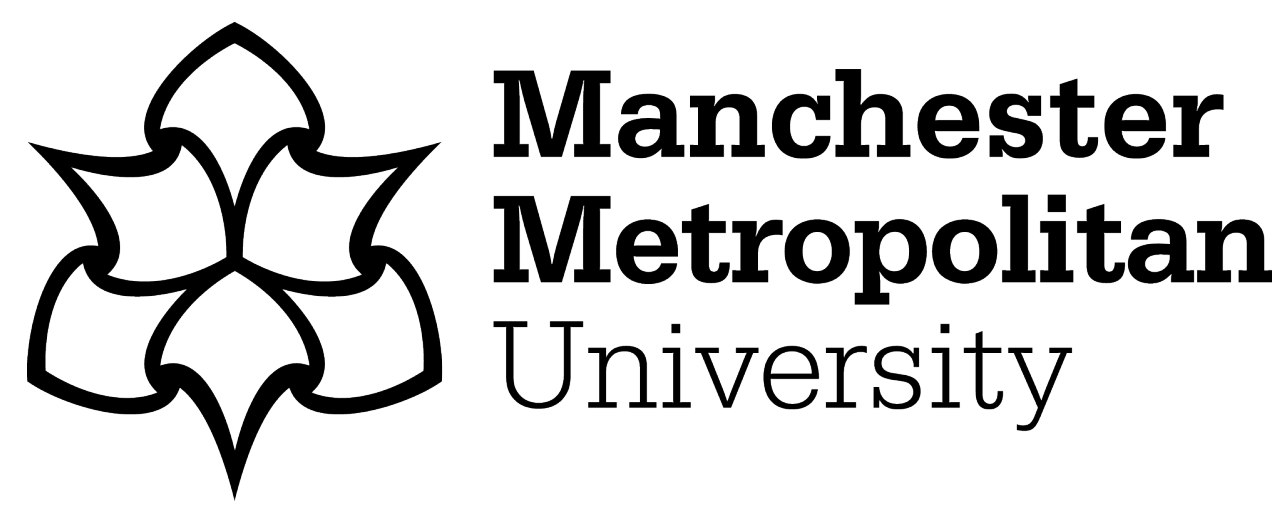

Adegbenjo, AO, Olubambi, PA, Potgieter, JH, Shongwe, MB and Ramakokovhu, M (2017) Spark plasma sintering of graphitized multi-walled carbon nanotube reinforced Ti6Al4V. Materials and Design, 128. pp. 119-129. ISSN 0264-1275

Downloaded from: https://e-space.mmu.ac.uk/620407/

Publisher: Elsevier

DOI: https://doi.org/10.1016/j.matdes.2017.05.003

Usage rights: Creative Commons: Attribution-Noncommercial-No Derivative Works 4.0

Please cite the published version 


\title{
Spark plasma sintering of graphitized multi-walled carbon nanotube reinforced Ti6Al4V
}

A.O. Adegbenjo ${ }^{a, *}$, P.A. Olubambi ${ }^{\mathrm{a}, \mathrm{b}}$, J.H. Potgieter ${ }^{\mathrm{c}}$, M.B.Shongwe ${ }^{\mathrm{a}}$ and M. Ramakokovhu ${ }^{\mathrm{a}}$

a. Institute for NanoEngineering Research, Department of Chemical, Metallurgical, and Materials Engineering, Tshwane University of Technology, South Africa.

b. Department of Chemical Engineering Technology, University of Johannesburg, South Africa.

c. School of Chemical and Metallurgical Engineering, University of The Witwatersrand, Johannesburg, South Africa.

* Correspondence: waleeleect@gmail.com

\begin{abstract}
Graphitized multi-walled carbon nanotubes $\left(\mathrm{MWCNT}_{\mathrm{Gr}}\right.$ ) reinforced Ti6Al4V (Ti64) matrix composites prepared via thepowder metallurgy route were synthesized by spark plasma sintering (SPS) technique. 1, 2 and $3 \mathrm{wt} \% \mathrm{MWCNT}_{\mathrm{Gr}}$ were dispersed in the Ti64 matrices by adapted high energy ball milling $\left(\mathrm{HEBM}_{\mathrm{A}}\right)$. Composite powder mixtures were sintered in vacuum at constant applied pressure, heating rate and isothermal holding time of $50 \mathrm{MPa}, 100{ }^{\circ} \mathrm{C} / \mathrm{min}$ and $5 \mathrm{~min}$ respectively. Thesintering temperature was varied between 850 and $1000{ }^{\circ} \mathrm{C}$.Scanning electron microscopy (SEM), transmission electron microscopy (TEM) and X-ray diffraction (XRD)were used to characterize the as-received MWCNTs, MWCNT $_{\mathrm{Gr}}$, admixed composite powders and the bulk sintered composites. MWCNT $_{\text {Gr }}$ evolution during graphitization treatment, dispersion in Ti64 matrix and in the sintered composites was analyzed using the characteristic Raman peak intensity ratio $\left(\mathrm{I}_{\mathrm{D}} / \mathrm{I}_{\mathrm{G}}\right)$. The relative density of the sintered $\mathrm{MWCNT}_{\mathrm{Gr}} / \mathrm{Ti} 64$ composites was enhanced with increased sintering temperature, but deteriorated with increased wt \% $\mathrm{MWCNT}_{\mathrm{Gr}}$ in the metal matrix. Vickers microhardness of the consolidated composites improved with increasing sintering temperature and weight fractions of $\mathrm{MWCNT}_{\mathrm{Gr}}$ over that of the unreinforced matrix alloy. The formation of crystalline $\mathrm{TiC}$ interfacial product during composite powder processing and consolidationis also discussed.
\end{abstract}

Keywords: Metal matrix composites; Reinforcement; MWCNT dispersion; Interfacial reaction; Graphitization 


\section{Introduction}

Aluminium (Al) and magnesium (Mg)lightmetalshave been extensively studied as structural materials for aerospace applications, although they lack the strength and rigidity attainable with iron and steel [1]. Over the years, Al and its alloys have been the mostly employed promising lightweight materials in this industry for improved fuel efficiency and control of $\mathrm{CO}_{2}$ emissions. However,they are seldom used lately due to the harsh, fluctuating and high operating conditions that aerospace materials are subjected to in service [2].Hence, this pressing demand for high strength and lightweight materials hasinspired researchers to find alternative materials for $\mathrm{Al}$ and its alloys in aerospace applications[3].

Recently, titanium (Ti) and its alloys have been explored in the aerospace industry for weight savings (to replace steel and Al primarily), space limitation (as Al alloys replacement), high operating temperature ( $\mathrm{Al}$, steel and $\mathrm{Ni}$-based alloys replacement), corrosion resistance (to replace low alloy steels and Al) and composite compatibility (replace Al alloys)[2, 4]. Nevertheless, Ti materials do exhibit inferior hardness, Young's modulus, heat and wear resistanceswhen compared to steel and Ni-based alloys [4-6]. Consequently, Ti-matrix composites (TMC) with different reinforcement materials such as TiB whiskers [7-9], TiC particles [10-12], SiC fibers [13, 14]and particles [15], $\mathrm{TiB}_{2}[16], \mathrm{SiO}_{2}[17]$ and carbon nanotubes $[5,18]$ have been reported.

Among these reinforcement materials, the development of high performance, smart TMCs for diverse engineering applications havebeen modified withcarbon nanotubes (CNTs) as reinforcementin recent years. CNTs are attractive from the point of view of their superior mechanical, thermal and electrical properties, high aspect ratios and low densities[19-23].However, there are very few reports in literature on Ti metal matrix being reinforced with CNTs, due to the associated processing challenges often encountered when reinforcing metal matrices with CNTs [24].

The processing challenges reported in previous studies are (i) achieving and maintaining the homogeneous dispersion of CNTs in the metal matrix, (ii) damage to CNTs during processing resultingin interfacial reactions with the matrix and (iii) weak bonding with the matrix $[19,25,26]$. Also, Feng et al.[27] and Munir et al.[23] have reported that high sintering temperatures promote interfacial reaction between Ti and defective multi-walled CNTs (MWCNTs). To overcome these challenges, the use of graphitized MWCNTs $\left(\mathrm{MWCNT}_{\mathrm{Gr}}\right.$ ) has been reported to be beneficial for controlling interfacial reactions with the metal matrix, while Ti and its alloys in combination with 
the advantages derivable from powder metallurgy techniques can offer interesting possibilities to the development andfabrication of CNTs reinforced TMCs[5, 27].

Although a few reports are available in literature on the reinforcement of Ti matrix with MWCNTs, none of these studies has to date reported on the reinforcement of Ti64with MWCNTs, to the best of our knowledge. In addition, Weston et al.[28]stated that little attention has been given to the processing of Ti alloy powders by the SPS route. Zhang et al. [29]also reported that a significant gap still exists in the fundamental understanding of the SPS mechanisms. This gap was attributed to the complex nature of the electrical, thermal and mechanical processes involved during SPS and their dependence on the SPS parameters. Consequently, the availability of data on SPS mechanisms during sintering processes are largely limited [29, 30].Therefore, this present studyexplored the advantages of SPS (rapid heating rate, low sintering temperature, short sintering cycle and fast cooling rate) as an advanced sintering technique to synthesize admixed $\mathrm{MWCNT}_{\mathrm{Gr}} / \mathrm{Ti} 64$ metal matrix composite powdersaimed at controlling the characteristic challenge of interfacial reactions in fabricating CNT reinforced TMCs. The influence of sintering temperature and weight fraction of $\mathrm{MWCNT}_{\mathrm{Gr}}$ on the densification, microstructure, microhardness and fracture characteristics of the consolidated composites were investigated.

\section{Experimental}

The starting powder materials used for this study were MWCNTs (Cheap Tubes Inc., USA, with outside diameter $(\mathrm{OD})=20-30 \mathrm{~nm}$, length $(\mathrm{L})=10-30 \mu \mathrm{m}$, ash $<1.5 \mathrm{wt} \%$, purity $>95 \mathrm{wt} \%$ ) and argon atomized, prealloyed Ti64(-25 $\mu \mathrm{m}$ particle size), supplied by TLS Technik GmbH \& Co., Germany.The as-received MWCNTs were graphitized by high-temperature annealingfor $5 \mathrm{~h}$ at $1800{ }^{\circ} \mathrm{C}$ in vacuum, using a Webb 77 Natick MA, USA tube furnace. The heating rate to the graphitization temperature was set at $10^{\circ} \mathrm{C} / \mathrm{min}$.

Thereafter, the Retsch PM 400 MA, Germany, high energy ball mill (HEBM), was adapted for the mixing and dispersion of 1,2 and $3 \mathrm{wt} \% \mathrm{MWCNT}_{\mathrm{Gr}}$ in the Ti64 metal matrix. The dispersion parameters were chosen such that the ball mill was used as a mixing medium rather than as a milling medium. Thus, neither size reduction nor fracturing of the matrix powder particles was expected to occur. This was also done to minimize the generation of non-sp ${ }^{2}$ structural defects in

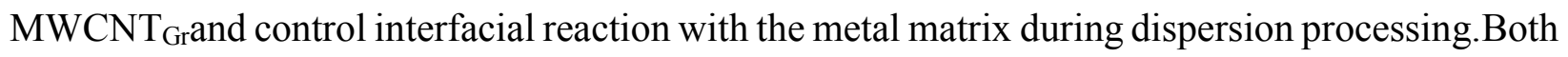
the matrix alloy powder and the measured wt $\% \mathrm{MWCNT}_{\mathrm{Gr}}$ were charged into stainless steel vials ( $250 \mathrm{ml}$ capacity) with stainless steel balls of three different sizes (diameter $(\mathrm{d})=3,5$ and $7 \mathrm{~mm}$ ). 
The reason for using three different ball sizes was to prevent the charged powders from cold welding and to increase the collision energy available to the powder particles[31, 32]. These were mixed for $6 \mathrm{~h}$ at a rotational speed of $50 \mathrm{rpm}$. The ball to powder ratio (BPR) used was 10:1 while the ball mill was set to stopat intervals of $10 \mathrm{~min}$ for every $10 \mathrm{~min}$ of mixing. This was done to avoid cold welding of the powders and also prevent them from getting heated up due to excessive frictional and impact forces from ball-powder-ball interactions.

The starting powders and the admixed $\mathrm{MWCNT}_{\mathrm{Gr}} / \mathrm{Ti} 64$ composite powders were characterized by scanning electron microscopes(High Resolution Field Emission SEM (JSM-7600F, JEOL, Japan) and Zeiss Ultra Plus, Germany)) with incorporated energy dispersive X-ray spectrometry (EDX) facilities. Atransmission electron microscope (JEOL JEM-2100F) was employed to study the surface morphologies and microstructure of the powders. Structural changes and crystalline phase identification studies of the composite powders were also performed by X-ray diffraction (PANalyticalEmpyrean model), with $\mathrm{Cu} \mathrm{K} \alpha$ radiation $(\lambda=0.154 \mathrm{~nm}$ ) at a scan rate of $1 \%$ min over a $10-90^{\circ}$ angular range.The results were analyzed with Highscore plus software. The MWCNTGrand admixed composite powders were characterized by Raman spectroscopy (T6400 Jobin Yvon, HORIBA, Japan)with a $514.5 \mathrm{~nm}$ laser employing a 20x objective lens. The spectra range used, was between 200 and $2000 \mathrm{~cm}^{-1}$.

The admixed MWCNTGr/Ti64 composite powders in this work were consolidated by a SPS model HHPD-25, FCT Germany. Predetermined amounts of the composite powders were poured into a Ø $40 \mathrm{mmgraphite}$ die targeted at $5 \mathrm{~mm}$ thickness after sintering. The quantity of powder $Q$, expected to attain a desired composite disc thickness Tof the sintered sample when fully dense, was calculated from Eq. 1. $D_{c}$ is the theoretical density of the composite and $r$ is the radius of the graphite die. $D_{c}$ is calculated from Eq. 2 according to the rule of mixtures. $W_{m}$ and $W_{f}$ are the weight fractions of the Ti6A14V matrix and MWCNTs reinforcement powders used respectively. $D_{m}$ and $D_{f}$ are the densities of Ti6Al4V $\left(4.43 \mathrm{~g} / \mathrm{cm}^{3}\right)$ and MWCNTs $\left(2.1 \mathrm{~g} / \mathrm{cm}^{3}\right)$ respectively.

$Q=D_{c} T \pi r^{2}$

$\frac{1}{D_{c}}=\frac{W_{m}}{D_{m}}+\frac{W_{f}}{D_{f}}$

Graphite foils were placed between the powder and the graphite die to prevent powder welding and ensure uniform current flow within it. Composite powders were sintered in successive runs 
atconstant heating rate, applied pressure and holding time of $100^{\circ} \mathrm{C} / \mathrm{min}, 50 \mathrm{MPa}$ and $5 \mathrm{~min}$ respectively in vacuum. The sintering temperature was varied between 850 and $1000{ }^{\circ} \mathrm{C}$.An optical pyrometer embedded within the upper punch was used to record the temperature within the sample core as the sintering experiment progressed.A pre-compaction force of $10 \mathrm{kN}$ was applied at the onset of the SPS cycle to create good electrical contact between the powder and the die assembly. The densities of the consolidated composite samples were measured following Archimedes' principle at room temperature according to ASTM B962.The recorded density was an arithmetic mean of five different measurements taken from the same sample.Relative densities werecalculated as a percentage of the calculated composite theoretical densities.

Microhardness measurementswere carriedout on sectioned as-polished sintered sample surfacesat room temperature under a load of 500 gfand dwell time of $15 \mathrm{~s}$, according to ASTM E384. The reported hardness value for each sample is an arithmetic mean of ten successive indentations made on the as polished sample surface. The microstructure, fracture surfaces, structural and crystalline phase changes and the evolution of $\mathrm{MWCNT}_{\mathrm{Gr}}$ in the consolidated samples were characterized by SEM, XRD and Raman spectroscopy respectively.The mirror polished samples were etched with

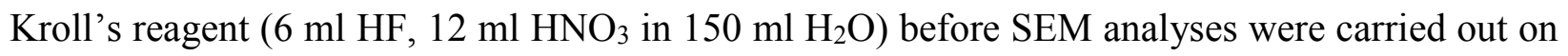
them.

\section{Results and discussion}

\subsection{Characterization of starting and admixed composite powders}

Fig. 1 shows the morphologies of the starting powders used in this study. The as-received Ti64 metal matrix alloy powder (Fig. 1a) has spherical shaped particles (particle size $=-25 \mu \mathrm{m}$ and particle size distribution $(\mathrm{PSD}): \mathrm{D} 10=9.12 \mu \mathrm{m}, \mathrm{D} 50=19.04 \mu \mathrm{m}$ and $\mathrm{D} 90=28.01$ $\mu \mathrm{m})$ characteristic of a gas atomized process. There was no evidence of agglomeration in the particles. The SEM image of the as-received MWCNT is presented in Fig. 1b, while its TEM image is shown in Fig. 1c. The MWCNTs are highly entangled and contained some amorphous carbon, retained metal catalysts and carbonaceous nanoparticles (these are seen as black spots, indicated by arrowsin the TEM image) as identified from previous studies [28, 33].

The SEM micrograph of MWCNT Gris shown in Fig. 2a. The Raman spectra of the as-received

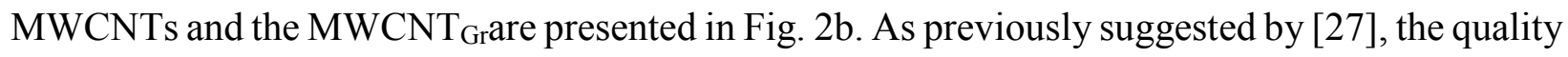


of MWCNTs is improved when subjected to graphitization treatment. This helps to reducedefects in MWCNTs and control interfacial reactions with metal matrices during processing.

The MWCNT $_{\text {Gr }}$ (Fig. 2b (ii)) had two characteristic graphitic peaks at 1340 and $1570 \mathrm{~cm}^{-1}$, which corresponds to the D and $\mathrm{G}$ bands respectively $[34,35]$. The $\mathrm{MWCNT}_{\mathrm{Gr}}$ showed a higher intensityG band peakat a wavenumber of $1570 \mathrm{~cm}^{-1}$ compared to that exhibited by the as-received MWCNTs at $1565 \mathrm{~cm}^{-1}$ (Fig. 2b (i)). Although the observed shift to a higher wavenumber in $\mathrm{MWCNT}_{\mathrm{Gr}}$ has been attributed to stresses induced during treatment [36], the increase in the G band peak height is ratheran indication of higher graphite crystallization and chemical stability [27]. The Raman peak ratio $\left(\mathrm{I}_{\mathrm{D}} / \mathrm{I}_{\mathrm{G}}\right)$ reduced from 0.9 in the as-received MWCNTs to 0.8 in the $\mathrm{MWCNT}_{\mathrm{Gr}}$ translating to $11 \%$ improvement in graphite crystallization and increased graphite formation. This is evident in the narrower $\mathrm{G}$ band peak for the $\mathrm{MWCNT}_{\mathrm{Gr}}$.

Fig. 3 shows the SEM micrographs of the admixed MWCNT $\mathrm{Gr}_{\mathrm{Gr}} / \mathrm{Ti64}$ composite powderstaken at low and high magnifications after $6 \mathrm{~h}$ mixing in the planetary ball mill.The dispersed MWCNT $_{\text {Grpowders }}$ were seen coating the Ti64 particles (indicated by arrows in Figs. 3a-c). The higher magnification images (Figs. 3d-f) showed unbundled $\mathrm{MWCNT}_{\mathrm{Gr}}$ (indicated by arrows) were dispersed in the Ti64 matrices at the different wt \% MWCNT ${ }_{\mathrm{Gr}}$ in the matrix alloy. However, it was observed that the degree of $\mathrm{MWCNT}_{\mathrm{Gr}}$ dispersion reduced with the increased wt $\%$ $\mathrm{MWCNT}_{\mathrm{Gr}}$ in the metal matrix. The $\mathrm{MWCNT}_{\mathrm{Gr}}$ were relatively dispersedhomogeneouslyin the composite powder with $1 \mathrm{wt} \% \mathrm{MWCNT}_{\text {Gr }}$ (Fig. 3d) while clustered and agglomerated $\mathrm{MWCNT}_{\mathrm{Gr}}$ (indicated by "P") were observedin the composite powders with 2 and 3 wt \% MWCNT ${ }_{\text {Gr }}$ respectively (Figs. 3e-f). This difficulty in unbundling $\mathrm{MWCNT}_{\mathrm{Gr}}$ as its wt $\%$ increased within the matrix was partly due to the high aspect ratio, large surface area and the nano-size dimensions of MWCNT $_{\text {Gr. Other factors include the characteristic tubular morphology and predominantly strong }}$ Van der Waals forces in the individual tubes which become stronger with the increased amount of $\operatorname{MWCNT}_{\text {Gr }}$ in the matrix $[24,37,38]$.

Despite the fact that the $\mathrm{MWCNT}_{\mathrm{Gr}}$ were dispersed into the matrix powder by dry $\mathrm{HEBM}_{\mathrm{A}}$ and without the use of any PCA, there was no trace of cold welding in the admixed composite powders and particles of the metal matrix alloy maintained their original sizes and structure reasonably (Figs. 3a-c). No fracturing of the particles occurred.The presumed mechanism of $\mathrm{MWCNT}_{\mathrm{Gr}}$ dispersion in Ti64 matrix was by diffusion (a gentle random motion distributing individual Ti64 particles throughout the powder mixture), convection (fast random motion which breaks down and 
distributes agglomerates of CNT into the powder mixture) and shear (enhanced or robust particle movement by agitation, caused by powder-to-powder, powder-to-ball and powder-ball-vial wall interactions) as opposed to plastic deformation, welding and fracturing. It was affirmed that the dispersion process parameters used in this study during $\mathrm{HEBM}_{\mathrm{A}}$ actually promoted the dispersion of $\mathrm{MWCNT}_{\mathrm{Gr}}$ by mixing rather than milling. This observation is a significant departure from most of the available previous studies where mild to severe cold welding was reported during either dry or wet dispersion of MWCNTs in Ti matrices by HEBM, even in the presence of a PCA [31, 3739].However, the result of this present study agrees with the previous study by Bhatet al.[19] in which $\mathrm{CNTs}$ were dispersed into $\mathrm{Cu}-10 \mathrm{Sn}$ using a twin-roller mixer.It was reported that physical blending/mixing in the twin-roller mixer resulted in uniform and attachment of CNTs to the $\mathrm{Cu}$ $10 \mathrm{Sn}$ alloy powder without significant change in shape or size of the alloy powder.

The X-ray diffractionpatterns of $\mathrm{MWCNT}_{\mathrm{Gr}}$, as-received Ti64 and the admixed MWCNT $\mathrm{Gr}_{\mathrm{G}} / \mathrm{Ti64}$ composite powders are shown in Fig. 4. The composite powders showed $\alpha$-Ti peaks only, without evidence of peak broadening. Thisfurther corroborates the earlier position that there was no significant reduction in the sizes of the matrix Ti64 powder particles.MWCNT Gr $_{\text {peaks were not }}$ seen in the XRD patterns of the admixed composite powders. This may be due to the XRD limit of detection which is not sufficient to detect small fractions of the MWCNT Grin Ti64 matrix powders. It could also be as a result of the wide difference in the mass absorption coefficients of $\mathrm{Ti}$ and carbon (for $\mathrm{Cu} \mathrm{K \alpha}$ radiations) that are 208 and $4.6 \mathrm{~m}^{2} \mathrm{~g}^{-1}$ respectively, which often makes it difficult for XRD to detect $\mathrm{C}$ in the presence of Ti [23, 40, 41]. Furthermore, it may be inferred from similar work by Caiet al.[20], that the absence of MWCNT peaks in the XRD patterns could also be due to the homogeneous dispersion of $\mathrm{MWCNT}_{\mathrm{Gr}}$ in the Ti64 matrix or the amorphization of the MWCNT $_{\mathrm{Gr}}$.Amorphization of CNTs describes the process of making the structure of CNTs become amorphous, that is, any process that generates the presence of non-sp ${ }^{2}$ disorders/defects in the C-C network structure of CNTs. Ferrari and Robertson [42] identified three series of defects introduction in carbon based materials. These are: (i) bond-angle disorder, (ii) bond-length disorder and (iii) hybridization. A three-stage model for a typical amorphization trajectory was proposed by Lespade et al.[43] as: graphite $\rightarrow$ nanocrystalline graphite (nc-G), nc-G $\rightarrow$ a-C (amorphous carbon), and a-C $\rightarrow$ ta-C (tetrahedral amorphous carbon; where there is $\sim 85 \% \mathrm{sp}^{3}$ ta-C). An example of amorphization occurs during dispersion processing of CNTs into metal matrices. Munir et al. [44]have demonstrated this in their previous study. They stated that structural 
defects in MWCNTs may emerge mainly because of the energy absorbed by them during milling process via milling balls and the friction amongMWCNTs and neighboring Ti particles resulting to the formation of highly reactive $\mathrm{sp}^{3} \mathrm{C}-\mathrm{C}$ amorphous phases in MWCNTs.

Fig. 5 shows the results of the TEM observations conducted on the composite powders. For the powder containing $1 \mathrm{wt} \% \mathrm{MWCNT}_{\mathrm{Gr}}$ in the Ti64 alloy matrix, unbundled $\mathrm{MWCNT}_{\mathrm{Gr}}$ were well dispersed in the metal matrix as seen in Figs. 5a-b. Deformed MWCNT Gr $_{\text {was observed (indicated }}$ with arrow) in Fig. 5c. This kind of structural defect in the $\mathrm{C}-\mathrm{C}$ network of $\mathrm{MWCNT}_{\mathrm{Gr}}$ may be formed due to absorbed energy from the balls and frictional forces among neighboring Ti64 particles and $\mathrm{MWCNT}_{\mathrm{Gr}}$. This defect area is a potential site for the formation of interfacial products (such as TiC), owing to the interaction between the non-sp ${ }^{2}$ carbon defects and the Ti64 particles [44]. However, as the wt \% of $\mathrm{MWCNT}_{\mathrm{Gr}}$ increased to $2 \mathrm{wt} \%$ in the matrix powder, a large agglomerate of $\mathrm{MWCNT}_{\mathrm{Gr}}$ wasobserved in the matrix alloy (Fig. 5d). Fig. 5e also shows MWCNT $_{\mathrm{Gr}}$ in a large Ti64 particle. This suggests that the degree of dispersion of the

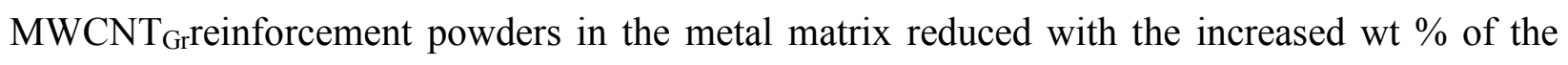
MWCNT $_{\text {Gr }}$ in the matrix. Fig. 5f shows some deformed MWCNT $_{\text {Gr. Nevertheless, individual }}$ nanotubes still maintained their tubular structure after the dispersion process. This is essential in order to ensure that the properties of interest in nanotubes are not lost. Otherwise, the properties and integrity of the final bulk composite will be compromised[23, 36, 38].The severity of $\mathrm{MWCNT}_{\mathrm{Gr}}$ destruction also increased with the increase in the weight fraction of the $\mathrm{MWCNT}_{\mathrm{Gr}}$ reinforcement in the metalmatrix (Figs. $5 \mathrm{f}$ and i). This was attributed to the increased difficulty in unbundling $\mathrm{MWCNT}_{\mathrm{Gr}}$ due to stronger Van der Waals forces. There is a higher tendency for agglomeration of the $\mathrm{MWCNT}_{\mathrm{Gr}}$. Hence, the increased interaction between the metal particles and MWCNT $_{\mathrm{Gr}}$ on one hand and between individual hard $\mathrm{MWCNT}_{\mathrm{Gr}}$ among themselves led to the observed defects in the $\mathrm{MWCNT}_{\mathrm{Gr}}$. However, no interfacial reaction products were observed in the TEM images which is in agreement with the XRD results earlier discussed in Fig. 4.

\subsection{X-ray diffraction patterns of sintered Ti64 and $M W C N T_{G r} /$ Ti64 composites}

The results of the analyses on the structural changes and crystalline phase evolution in the sintered unreinforced Ti64 and MWCNT ${ }_{\mathrm{Gr}} / \mathrm{Ti} 64$ composites as characterized by XRD are shown in Fig. 6. Fig. 6a revealed that the sintered unreinforced Ti64 contained the characteristic $\alpha$ - and $\beta$-Ti phases of Ti64 with the matrix being the $\alpha$-phase.There was no visible evidence of peak broadening in the peaks as the sintering temperature increased. The addition of MWCNT $_{\text {Gr }}$ to Ti64 (Fig. 6b-d) 
however showed the presence of crystalline $\mathrm{TiC}$ phases in the sintered composites aside from the $\alpha$ - and $\beta$-phases.It was observed that the TiC formation was dependent on sintering temperature and the weight fraction of $\mathrm{MWCNT}_{\mathrm{Gr}}$ in the composites. No TiC was formed in the composites below $900{ }^{\circ} \mathrm{C}$ at all the weight fractions of $\mathrm{MWCNT}_{\mathrm{Gr}}$ contained in the sintered composites. However, this does not suggest that $\mathrm{TiC}$ interfacial product could only be formed below $900{ }^{\circ} \mathrm{C}$ when defective MWCNTs react with Ti metal. Nevertheless, the observation in this present study agrees with the previous studyby Feng et al.[27], in which they concluded the reaction between defective graphitized MWCNTs and Ti is promoted by an increase in temperature and that the amount of $\mathrm{TiC}$ formation is limited below $980{ }^{\circ} \mathrm{C}$. Although an earlier report by Caiet $a l$.[20]indicated that the reaction between Ti and amorphous carbons in defective MWCNTs can occur at a temperature as low as $700{ }^{\circ} \mathrm{C}$ during SPS processing, this present study showed that the $\mathrm{HEBM}_{\mathrm{A}}$ method in combination with SPS can delay, and as wellcontrol, the interfacial reaction between Ti64 and defective MWCNT $_{\text {Gr. }}$. This affirms the findings of a similar study by Wang et al.[45] wherein they opined that short sintering cycles in SPS preservesthe structure of MWCNTs and may prevent the reaction between Ti and MWCNTs.

It was noticed that $\mathrm{TiC}$ only began to form in the composite with $1 \mathrm{wt} \% \mathrm{MWCNT}_{\mathrm{Gr}}$ at $950{ }^{\circ} \mathrm{C}$, even though the crystalline phase was observed in the other composites containing higher $\mathrm{MWCNT}_{\mathrm{Gr}}$ weight fractions at a lower temperature of $900{ }^{\circ} \mathrm{C}$. This suggests that a higher amorphous carbon content in the $\mathrm{MWCNT}_{\mathrm{Gr}}$ reinforcement caused by damages during powder processing (owing to difficulty in un-bundling and achieving adequate dispersion of $\mathrm{MWCNT}_{\mathrm{Gr}}$ ) at increased weight fractions of $\mathrm{MWCNT}_{\mathrm{Gr}}$ lowers the activation energy needed for the TiC phase formation during sintering.Consequently, the reaction temperature between the defective MWCNT $_{\text {Gr }}$ and Ti64 was lowered as it is presumed that the amount of defective

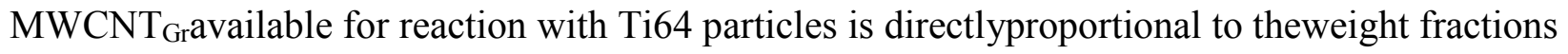
of $\mathrm{MWCNT}_{\mathrm{Gr}}$ in the composites. This corroborates the position reported by Munir et al. [23, 38] that interfacial reactions during high temperature composite processing are triggered by the presence of severely deformed MWCNTs in a Ti matrix.

The XRD patterns of the composites containing 1 and $2 \mathrm{wt} \%$ MWCNT $_{\text {Grrespectively showed }}$ peaks of retained $\mathrm{MWCNT}_{\mathrm{Gr}}$ between 900 and $1000{ }^{\circ} \mathrm{C}$. This high temperature retention of $\mathrm{MWCNT}_{\mathrm{Gr}}$ as stated previously [20]is an indication that the interfacial reaction between MWCNTs and metal matrices can be controlled by improving the MWCNTs quality. This assertion is 
supported by the results obtained from this present study as the $\mathrm{TiC}$ peaks in the sintered composites showed less intense peaks, suggesting that the interfacial reaction was largely controlled.

\subsection{Microstructure of sintered Ti64 and $M W C N T_{G r} / T i 64$ composites}

The secondary electron images (SEI) of unreinforced Ti64 and MWCNT $\mathrm{Mr}_{\mathrm{Gr}} / \mathrm{Ti}^{6} 4$ composites (with varied weight fractions of the $\mathrm{MWCNT}_{\mathrm{Gr}}$ reinforcements), sintered at 850 and $1000{ }^{\circ} \mathrm{C}$ respectively areshown in Fig. 7. The unreinforced Ti64 sintered at 850 and $1000^{\circ} \mathrm{C}$ showed a near lamellar and fully lamellar microstructure respectively, with the characteristic Widmanstätten (basket weave) $\alpha+\beta$ network structure of Ti64 (Figs. 7a and b). The $\alpha$-phase (grey) matrix contained the $\beta$-phase (white) on the $\alpha$ grain boundaries. At $1000{ }^{\circ} \mathrm{C}$ (Fig. $7 \mathrm{~b}$ ), the Widmanstättenlike microstructure is more prominent with the $\beta$-phase more elongated. There are more pores in the microstructure at $850^{\circ} \mathrm{C}$, whereas the pores are fewer and closed up at the higher sintering temperature. This is expected as sintering kinetics and atom diffusion are enhanced at high temperatures.

With the addition of $\mathrm{MWCNT}_{\mathrm{Gr}}$ to Ti64, the micrographs of the sintered composites exhibited equiaxed microstructures consisting of $\alpha$ and $\beta$ phases. They showed similar pore characteristics as the sintered unreinforced Ti64 at 850 and $1000{ }^{\circ} \mathrm{C}$ respectively. However, it was observed that at the lower sintering temperature, the amount of pores in the composites increased with the increasing weight fraction of $\mathrm{MWCNT}_{\mathrm{Gr}}$. This may be attributed to the difficulty in sintering due to insufficient diffusion between Ti64 and $\mathrm{MWCNT}_{\mathrm{Gr}}$,as well as the inadequate dispersion of $\mathrm{MWCNT}_{\mathrm{Gr}}$ in the metal matrix owing to the re-agglomeration of $\mathrm{MWCNT}_{\mathrm{Gr}}$ (depicted as retained CNT in Figs. 7e-g) as its weight fraction increased within the composites. This MWCNTGrreagglomeration is known to promote interfacial reaction with the metal matrix [37]. This can be ascribed to inadequate $\mathrm{MWCNT}_{\mathrm{Gr}}$ dispersion during powder processing, which is evident from Figs. $3 \mathrm{e}$ and $\mathrm{f}$. The effect of this is seen as the clustering of TiC particles in the composite with 3 wt \% $\mathrm{MWCNT}_{\mathrm{Gr}}$ (Fig. 7h) as the interfacial products are assumed to be formed around clustered retained MWCNT $_{\mathrm{Gr}}$, which isin agreement with previous studies[37, 38]. The composite with $1 \mathrm{wt}$ $\% \mathrm{MWCNT}_{\mathrm{Gr}}$ and sintered at $1000{ }^{\circ} \mathrm{C}$ showed a fully dense, fine, equi-axed $\alpha+\beta$ structure with no evidence of pores and retained (or re-agglomerated) $\mathrm{MWCNT}_{\mathrm{Gr}}$, which further affirms the effective dispersion of $\mathrm{MWCNT}_{\mathrm{Gr}}$ during powder processing. 


\subsection{Raman spectra of sintered $M W C N T_{G r} / T i 64$ composites}

Raman spectroscopy has been a universally accepted tool for characterizing the evolution of the $\mathrm{sp}^{2} \mathrm{C}-\mathrm{C}$ network of MWCNTs during composite processing [36, 37, 44]. In this study, it was necessary to first characterize the evolution of the $\mathrm{MWCNT}_{\mathrm{Gr}}$ during the composite powder processing by $\mathrm{HEBM}_{\mathrm{A}}$, in order to fully understand the evolution of $\mathrm{MWCNT}_{\mathrm{Gr}}$ in the sintered composites. Fig. 8 shows the Raman spectra of as-received Ti64, MWCNT Gr $_{\text {and }}$ the admixed composite powders.

The Raman spectra of the as-received Ti64 powder (Fig. 8a) did not exhibit any peaks as Ti (similar to most metals) does not show active Raman vibrational modes [40]. Two graphitic peaks at 1340 and $1570 \mathrm{~cm}^{-1}$ were seen in the $\mathrm{MWCNT}_{\mathrm{Gr}}$ (Fig. 8b) as earlier stated. These correspond to the D and $\mathrm{G}$ bands respectively with $\mathrm{I}_{\mathrm{D}} / \mathrm{I}_{\mathrm{G}}$ ratio $=0.8$. The composite powder with $1 \mathrm{wt} \% \mathrm{MWCNT}_{\mathrm{Gr}}$ (Fig. 8c) had D and G bands respectively at 1342 and $1581 \mathrm{~cm}^{-1}$. The shifting of the D band to a higher wavenumber was due to the stresses induced in the $\mathrm{MWCNT}_{\mathrm{Gr}} \mathrm{during}$ composite powder mixing $[46,47]$. The characteristic $\mathrm{I}_{\mathrm{D}} / \mathrm{I}_{\mathrm{G}}$ ratio increased to 1.01 , which is a $26 \%$ increase from that of the starting $\mathrm{MWCNT}_{\mathrm{Gr}}$. In a similar manner, $\mathrm{I}_{\mathrm{D}} / \mathrm{I}_{\mathrm{G}}=0.97$ for the $2 \mathrm{wt} \% \mathrm{MWCNT}_{\mathrm{Gr}}$ composite powder. This translated to a $21 \%$ increase compared to the as-received $\mathrm{MWCNT}_{\mathrm{Gr}}$, but is $5 \%$ less than that for the composite powder with $1 \mathrm{wt} \% \mathrm{MWCNT}_{\mathrm{Gr}}$. However, the $\mathrm{I}_{\mathrm{D}} / \mathrm{I}_{\mathrm{G}}$ ratio for the composite powder with 3 wt \% MWCNT $_{\mathrm{Gr}}$ could not be determined as the D and G band peaks had disappeared due to the amorphization of the $\mathrm{MWCNT}_{\mathrm{Gr}}$.

It is a generally accepted opinion that the structural integrity of MWCNTs is measured by the $\mathrm{I}_{\mathrm{D}} / \mathrm{I}_{\mathrm{G}}$ ratio. The deterioration of MWCNTs in the form of non-sp ${ }^{2}$ defects and other amorphous carbonaceous materials within MWCNTs make the intensities of the graphitic peaks in MWCNTs to diminish, that is, when $\mathrm{I}_{\mathrm{D}} / \mathrm{I}_{\mathrm{G}}>1$. The more $\mathrm{I}_{\mathrm{D}} / \mathrm{I}_{\mathrm{G}}<1$, the better is the structural integrity of the MWCNTs. Therefore, if the intensities of the graphitic peaks become so low that $\mathrm{I}_{\mathrm{D}} / \mathrm{I}_{\mathrm{G}}$ cannot be determined, it then implies that the MWCNTs have become completely amorphous. Previous studies have indicated that significantly reduced Raman peaks in MWCNTs is an evidence of the extensive loss of crystallinity in MWCNTs and the presence of amorphous carbon phase [38, 42].According to Ferrari and Robertson [42], the Raman spectrum is determined by four factors: (i) the clustering of the $\mathrm{sp}^{2}$ phase, (ii) bond disorder, (iii) presence of $\mathrm{sp}^{2}$ rings and chains, and (iv) the $\mathrm{sp}^{2} / \mathrm{sp}^{3}$ ratio. These factors act as controlling forces on the shape of the Raman spectra. 
The $\mathrm{D}$ and $\mathrm{G}$ bands (Fig. 8) were progressively broadened with increasing wt $\% \mathrm{MWCNT}_{\mathrm{Gr}}$ in the metal matrix. Any broadening of the $\mathrm{G}$ band peak specifically is an evidence of induced disorders or loss of crystallinity as the $\mathrm{G}$ band represents the degree of pristine arrangement and crystallinity of the C-atoms in the graphitic network of MWCNTs[40]. It follows therefore, thatthe extensive loss of crystallinity and defect concentration due to amorphization of $\mathrm{MWCNT}_{\mathrm{Gr}}$ increased with higher wt $\%$ MWCNT $_{\text {Gr }}$ in Ti64 matrix during the mixing of the composite powders.Although the MWCNTs in the samples containing 1 and $2 \mathrm{wt} \%$ MWCNTs may have undergone amorphization also, the extent of amorphization is however directly proportional to the level of MWCNTs agglomeration. Furthermore, the higher the weight fraction of MWCNT in the matrix alloy, the more difficult it is to de-agglomerate or homogeneously disperse MWCNT in the Ti64 matrix. When CNTs are hugely agglomerated, interaction between the hard tubes due to high proximity leads to increased defects in the $\mathrm{sp}^{2} \mathrm{C}-\mathrm{C}$ structure of the CNTs [23].Therefore, it is expected that the sample with $3 \mathrm{wt} \% \mathrm{MWCNT}$ will undergo the most amorphization.

Fig. 9 shows the Raman spectra of unreinforced Ti64 and $\mathrm{MWCNT}_{\mathrm{Gr}} / \mathrm{Ti64}$ composites sintered at $1000{ }^{\circ} \mathrm{C}$. The sintered unreinforced Ti64 (Fig. 9a) as expected did not show any peaks since the alloy does not exhibit active Raman vibrational modes. The sintered composites containing 1 and $2 \mathrm{wt} \% \mathrm{MWCNT}_{\mathrm{Gr}}$ showed their D band peaks at the same wavenumber $\left(1345 \mathrm{~cm}^{-1}\right)$ while their $\mathrm{G}$ band peaks were respectively at 1585 and $1574 \mathrm{~cm}^{-1}$. Their $\mathrm{I}_{\mathrm{D}} / \mathrm{I}_{\mathrm{G}}$ ratios also were 0.97 and 0.83 respectively. These values when compared with the $\mathrm{I}_{\mathrm{D}} / \mathrm{I}_{\mathrm{G}}$ ratios for the corresponding composite powders after mixing as represented in Figs. $8 \mathrm{c}$ and $d$, showed that the $\mathrm{I}_{\mathrm{D}} / \mathrm{I}_{\mathrm{G}}$ ratios reduced by 4 and $14 \%$ respectively. The higher percentage reduction in the $\mathrm{I}_{\mathrm{D}} / \mathrm{I}_{\mathrm{G}}$ ratio for the composite with 2 wt \% MWCNT $\mathrm{Mr}_{\text {Gr }}$ is justified as it exhibited a much higher G band peak intensity (Fig. 9c) which is an indication that the quality of $\mathrm{MWCNT}_{\mathrm{Gr}}$ is preserved even at the highest sintering temperature of $1000{ }^{\circ} \mathrm{C}$.The re-agglomerated or retained $\mathrm{MWCNT}_{\mathrm{Gr}}$ had $\mathrm{I}_{\mathrm{D}} / \mathrm{I}_{\mathrm{G}}=0.83$ aftercomposite sintering, which is approximately the same as 0.8 for the as-received $\mathrm{MWCNT}_{\mathrm{Gr}}$.

The $\mathrm{I}_{\mathrm{D}} / \mathrm{I}_{\mathrm{G}}$ ratio for the composite with $3 \mathrm{wt} \% \mathrm{MWCNT}_{\mathrm{Gr}}$ could not be determined, just as it was observed for the composite powders at this level after mixing. There were no visible $\mathrm{D}$ and $\mathrm{G}$ band graphitic peaks in this composite after sintering. It is an indication that the $\mathrm{MWCNT}_{\mathrm{Gr}}$ were completely amorphous and extensively lost their crystallinity as a carryover of the damages to them during mixing. This suggests that non-sp ${ }^{2}$ disorders in the $\mathrm{C}-\mathrm{C}$ bond networks of MWCNT $_{\text {GrWere prevalent in the composite powders after mixing.Thesedisorders, as also reported }}$ 
earlier[37],were responsible for initiating the interfacial reactions between the highly damaged $\mathrm{MWCNT}_{\mathrm{Gr}}$ and Ti64 matrix particles during sintering at high temperature, leading to the formation of clustered TiC interfacial products as seen in Fig. 7h. The insufficient dispersion of MWCNT $\mathrm{Mr}_{\mathrm{G}}$ in the admixed composite powder (Fig. 3f) also enhanced this interfacial reaction [48]. The XRD scans (Fig. 6d) confirm these observations as there were noretained MWCNT $_{\text {Gr }}$ peaks in the sintered composites.

\subsection{Influence of sintering temperature on the densificationof $M W C N T_{G r} / T i 64$ composites}

The densification patterns in the sintered composites and the unreinforced matrix alloy are shown in Fig.10. The unreinforced Ti64 attained near theoretical density at all the sintering temperatures $\left(850-1000{ }^{\circ} \mathrm{C}\right)$ investigated in this study. The relative density increased from $98.8 \%$ to $99.6 \%$ between 850 and $1000{ }^{\circ} \mathrm{C}$ translating to a $0.8 \%$ increase. However, the measured relative density was constant between 900 and $950{ }^{\circ} \mathrm{C}$, while only a $0.1 \%$ increase (99.5 to $99.6 \%$ ) was observed between 950 and $1000{ }^{\circ} \mathrm{C}$. Nevertheless, an increase of $0.7 \%$ (98.8 to $99.5 \%$ ), which is almost equal to that observed between 850 and $1000{ }^{\circ} \mathrm{C}$, was recorded between 850 and 900 ${ }^{\circ} \mathrm{C}$. Theenhancements in densification with increased sintering temperature were attributed to improved diffusion bonding and atom mobility at high temperatures. The closure of pores at high temperature as seen in the microstructures in Fig. $7 \mathrm{~b}$, is also responsible for the improved densification. This suggests that raising the sintering temperature was an effective route of densification enhancement for the matrix alloy.

The densification pattern in the sintered compositesdisplayed a progressive reduction in the relative densities of the composites as the weight fractions of the reinforcement increased in the composites.This progressive reduction in the relative densities with increased $\mathrm{MWCNT}_{\mathrm{Gr}}$ weight fraction may be attributed to the agglomeration and clustering of $\mathrm{MWCNT}_{\mathrm{Gr}}$ in the metal matrix. It could also be due to weak interfacial bonding in the composites caused by the insufficient diffusion between Ti64 and $\mathrm{MWCNT}_{\mathrm{Gr}}$, which may result in thermal mismatch between the matrix and the reinforcement.

At $850{ }^{\circ} \mathrm{C}$, sintered relative density decreased from $99.8 \%$ in the unreinforced Ti64 to $96.3 \%$ in the composite with $3 \mathrm{wt} \% \mathrm{MWCNT}_{\mathrm{Gr}}$, translating to a $3.5 \%$ reduction. At $1000{ }^{\circ} \mathrm{C}$, the recorded reduction was $1.6 \%$ (that is, from 99.6 to $98 \%$ ). The reduction in the measured relative densities as $\mathrm{MWCNT}_{\mathrm{Gr}}$ weight fractions increased from 1 to $3 \mathrm{wt} \%$ at 850 and $1000{ }^{\circ} \mathrm{C}$ were 1.7 and 1.2 $\%$, respectively. The relative homogeneous dispersion of $\mathrm{MWCNT}_{\mathrm{Gr}}$ in the composite with $1 \mathrm{wt}$ 
$\% \operatorname{MWCNT}_{\mathrm{Gr}}$ (Fig. 3d) was responsible for its better relative density in comparison to the composites with 2 and $3 \mathrm{wt} \% \mathrm{MWCNT}_{\mathrm{Gr}}$ (Figs. 3e and f) respectively.These observations are in agreement with the reports of a similar study by Saheb et al.[49] on the reinforcement of Al alloys with CNTs. The higher relative density in the composite with $1 \mathrm{wt} \% \mathrm{MWCNT}_{\text {GrWas }}$ most probably due to the relative homogeneous dispersion of the $\mathrm{MWCNT}_{\mathrm{Gr}}$ within the metal matrix and not due to the supposed minor detrimental effect of a lower weight fraction of $\mathrm{MWCNT}_{\mathrm{Gr}}$. This position was premised on a previous study by Wang et al.[45] wherein the amount of MWCNT in pure Ti were $0.2,0.4,0.6,0.8$ and $1.0 \mathrm{wt} \%$. The relative densities of the composites decreased with increasing wt \% MWCNT (99.69, 99.44, 99.31, 99.13 and 99.01\%) respectively despite the small amounts of MWCNT used compared to those used in this present study. The report justifies the position intended in this current study that even very small increase of MWCNT in a metal matrix could be responsible for a decrease in relative density of the bulk composite. This is because the tendency for pre-agglomeration (during dispersion processing) and re-agglomeration of MWCNT (during SPS) increases with increased weight fractions of MWCNT in the metal matrix.All the composites in this study exhibited lower relative densities than the unreinforced alloy. However, they showeda similar trend of enhanced densification with increased sintering temperature. Between 850 and $1000{ }^{\circ} \mathrm{C}$, the relative densities improved by $1.2,0.5$ and $1.7 \%$ with 1,2 and $3 \mathrm{wt}$ $\% \mathrm{MWCNT}_{\mathrm{Gr}}$ respectively in the sintered composites.

\subsection{Hardness of consolidated $M W C N T_{G r} /$ Ti64 composites}

The variation of hardness inthe sintered $\mathrm{MWCNT}_{\mathrm{Gr}} / \mathrm{Ti6} 4$ composites and at different sintering temperatures, is presented in Fig. 11. It was observed that the hardness of the composites improved with increasing weight fractions of $\mathrm{MWCNT}_{\mathrm{Gr}}$ added to the Ti64 matrix alloy at all the sintering temperatures investigated in this study.Between 850 and $1000{ }^{\circ} \mathrm{C}$, the measured percentage increases in hardness were $2.2(370-378 \mathrm{HV}), 7.3(369-396 \mathrm{HV})$ and $15.7 \%(344-398 \mathrm{HV})$ as the weight fraction of $\mathrm{MWCNT}_{\mathrm{Gr}}$ was increased from 1, 2 to $3 \mathrm{wt} \%$ respectively.Comparing the hardness of the unreinforced Ti64 and the composite containing $3 \mathrm{wt} \% \mathrm{MWCNT}_{\mathrm{Gr}}$ at 850 and $1000{ }^{\circ} \mathrm{C}$ respectively, the observed hardness was enhanced by 2.7 and $10 \%$ respectively, as the measured hardness improved from 335 - $344 \mathrm{HV}$ and from $362-398 \mathrm{HV}$ at these temperaturesrespectively. The increase in microhardness with increased sintering temperature in both the unreinforced alloy and the composites was the result of pore closure and improved densification as the sintering temperature increased. The presence of the hard TiC interfacial 
product with increasing sintering temperature (Fig. 6), also contributed to the increased hardness. However, the increase in hardnessdespite the loss in densification that was observed (Fig. 10) with the increased $\mathrm{MWCNT}_{\mathrm{Gr}}$ weight fraction in the composites, was attributed to the presence of retained $\mathrm{MWCNT}_{\mathrm{Gr}}$ and crystalline TiC hard phases which formed due to the interfacial reaction between the defective $\mathrm{MWCNT}_{\mathrm{Gr}}$ and the metal matrix. These results are consistent with previous studies by $[21,50,51]$.

\subsection{Fracture characteristics $M W C N T_{G r} /$ Ti64 composites}

The fracture surfaces of unreinforced Ti64 and $\mathrm{MWCNT}_{\mathrm{Gr}} / \mathrm{Ti} 64$ composites sintered at $1000{ }^{\circ} \mathrm{C}$ are shown in Fig. 12. The fracture surface of the unreinforced Ti64 metal matrix alloy (Fig. 12a) showed typical dimpled fracture morphology of $\mathrm{Ti}$ and its alloys [50], suggesting that the sintered alloy underwent ductile fracture mode. Its particles were also well deformed (Fig. 12(a $\left.\mathrm{a}^{1}\right)$ ) implying good sample cohesion as a result of better sinterability during the SPS processing. However, the sample containing $1 \mathrm{wt} \% \mathrm{MWCNT}_{\mathrm{Gr}}$ showed a more dimpled structure, which suggests improved sample cohesion and inherently good metallurgical bonding between the Ti64 matrix and $\mathrm{MWCNT}_{\mathrm{Gr}}$ reinforcement. Fig. 12( $\left.\mathrm{b}^{1}\right)$ showed the $\mathrm{MWCNT}_{\mathrm{Gr}}$ still retained their sizes and structure, displayed good interfacial bonding with the matrix and were well-dispersed within the matrix. The binding strength displayed by this composite during fracture was attributed to these observed features. This is consistent with the findings of Wang et al.[45]. However, as the weight fraction of $\mathrm{MWCNT}_{\mathrm{Gr}}$ increased to 2 and $3 \mathrm{wt} \%$ respectively in the Ti64 matrix, the dimples on the fracture surfaces of the composites reduced drastically (Fig. 12c-d), with only faint traces of the dimples left. This implies the fracture pattern in these samples were a combination of ductile and brittle fractures, the most prevalent being the latter. High magnification images of the areas within the white circles in Figs. 12c and d represented in Figs. $12 \mathrm{c}^{1}$ and $\mathrm{d}^{1}$ respectively showed highly agglomerated $\mathrm{MWCNT}_{\mathrm{Gr}}$ that are isolated from the matrix. This is because it becomes increasingly difficult to effectively disperse $\mathrm{MWCNT}_{\text {Gr }}$ within the metal matrix as their weight fractions are increased in the composite matrix.This resulted in the observed weak interfacial bonding between the matrix and the reinforcement.Observing the fracture surfaces of these composites, the features displayed showed the prevalent fracture modes in these composites wereMWCNT Gr pull out from the matrix particles. That is, there occurs interfacial isolation of $\mathrm{MWCNT}_{\mathrm{Gr}}$ from the Ti64 matrix, cleavage of Ti64 matrix particles and tensile fracture of $\mathrm{MWCNT}_{\mathrm{Gr}}$. These observations are in agreement with the conclusions previously reported by Wang et al. [45] and Li et al.[5]. 


\section{Conclusions}

Graphitized multi-walled carbon nanotube reinforced Ti64 composites were successfully synthesized by spark plasma sintering. The $\mathrm{HEBM}_{\mathrm{A}}$ methodexplored for the dispersion of MWCNT $_{\mathrm{Gr}}$ in Ti64 matrix ensured that no interfacial reaction between the metal matrix and defective MWCNT $_{\mathrm{Gr}} \mathrm{Occurred}$ during mixing. The presence of the retained $\mathrm{MWCNT}_{\mathrm{Gr}}$ in the consolidated composites at high temperatures indicates that subjecting the MWCNTs to graphitization treatment in combination with composite consolidation by SPS can control or delay the interfacial reactionduring sintering. The relative densities of the sintered composites improved with sintering temperature, but declined with increased weight fractions of $\mathrm{MWCNT}_{\mathrm{Gr}}$ in the composites due to inadequate dispersion or re-agglomeration of the $\mathrm{MWCNT}_{\mathrm{Gr}}$ and weak interfacial bonding between the matrix and reinforcement. The observed microhardness increased with increased sintering temperature and $\mathrm{MWCNT}_{\mathrm{Gr}}$ weight fractions in the composites. The prevalent fracture mechanism in the composites was by $\mathrm{MWCNT}_{\mathrm{Gr}}$ pull out from the matrix particles.

\section{Acknowledgement}

Tshwane University of Technology and Institute for NanoEngineering Research (INER) are appreciated for the conducive laboratory environment in support of this research.

\section{References}

[1] Noguchi T, Magario A, Fukazawa S, Shimizu S, Beppu J, Seki M. Carbon nanotube/aluminium composites with uniform dispersion. Materials Transactions. 2004;45:602-4.

[2] Henriques VAR, Campos PPd, Cairo CAA, Bressiani JC. Production of titanium alloys for advanced aerospace systems by powder metallurgy. Materials Research. 2005;8:443-6.

[3] Durowoju M, Sadiku E, Diouf S, Shongwe M, Olubambi P. Spark plasma sintering of graphite-aluminum powder reinforced with SiC/Si particles. Powder Technology. 2015;284:504-13.

[4] Veiga C, Davim J, Loureiro A. Properties and applications of titanium alloys: a brief review. Rev Adv Mater Sci. 2012;32:133-48.

[5] Li S, Sun B, Imai H, Mimoto T, Kondoh K. Powder metallurgy titanium metal matrix composites reinforced with carbon nanotubes and graphite. Composites Part A: Applied Science and Manufacturing. 2013;48:57-66.

[6] Kuzumaki T, Ujiie O, Ichinose $\mathrm{H}$, Ito $\mathrm{K}$. Mechanical characteristics and preparation of carbon nanotube fiber-reinforced Ti composite. Advanced Engineering Materials. 2000;2:416-8.

[7] Ni D, Geng L, Zhang J, Zheng Z. Effect of B 4 C particle size on microstructure of in situ titanium matrix composites prepared by reactive processing of Ti-B 4 C system. Scripta materialia. 2006;55:429-32. 
[8] Patel V, El-Desouky A, Garay J, Morsi K. Pressure-less and current-activated pressure-assisted sintering of titanium dual matrix composites: Effect of reinforcement particle size. Materials Science and Engineering: A. 2009;507:161-6.

[9] Wang M-m, Lu W-j, Qin J, Ma F, Lu J, Zhang D. Effect of volume fraction of reinforcement on room temperature tensile property of in situ (TiB+ TiC)/Ti matrix composites. Materials \& design. 2006;27:4948.

[10] Liu B, Liu Y, He X, Tang H, Chen L, Huang B. Preparation and mechanical properties of particulatereinforced powder metallurgy titanium matrix composites. Metallurgical and Materials Transactions $A$. 2007;38:2825-31.

[11] da Silva AA, dos Santos JF, Strohaecker TR. An investigation of the fracture behaviour of diffusionbonded Ti6Al4V/TiC/10p. Composites science and technology. 2006;66:2063-8.

[12] Wang F, Mei J, Wu X. Compositionally graded Ti6Al4V+ TiC made by direct laser fabrication using powder and wire. Materials \& design. 2007;28:2040-6.

[13] Yuan M-n, Yang Y-q, Huang B, Li J-K, Yan C. Evaluation of interface fracture toughness in SiC fiber reinforced titanium matrix composite. Transactions of Nonferrous Metals Society of China. 2008;18:9259.

[14] Kaya F, Bowen P, Liu J. In-situ observation of crack opening displacement (COD) in a metastable $\beta$ titanium composite. Journal of materials science. 2008;43:270-80.

[15] Selamat M, Watson L, Baker T. XRD and XPS studies on surface MMC layer of SiC reinforced Ti-6Al4V alloy. Journal of Materials Processing Technology. 2003;142:725-37.

[16] Lieberman S, Gokhale A, Tamirisakandala S, Bhat R. Three-dimensional microstructural characterization of discontinuously reinforced Ti64-TiB composites produced via blended elemental powder metallurgy. Materials Characterization. 2009;60:957-63.

[17] Han C, Li Y, Wu X, Ren S, San X, Zhu X. Ti/SiO 2 composite fabricated by powder metallurgy for orthopedic implant. Materials \& Design. 2013;49:76-80.

[18] Meléndez IM, Neubauer E, Danninger H. Consolidation of titanium matrix composites to maximum density by different hot pressing techniques. Materials Science and Engineering: A. 2010;527:4466-73.

[19] Bhat A, Balla VK, Bysakh S, Basu D, Bose S, Bandyopadhyay A. Carbon nanotube reinforced Cu-10Sn alloy composites: Mechanical and thermal properties. Materials Science and Engineering: $A$. 2011;528:6727-32.

[20] Cai W, Feng X, Sui J. Preparation of multi-walled carbon nanotube-reinforced TiNi matrix composites from elemental powders by spark plasma sintering. Rare Metals. 2012;31:48-50.

[21] Xue F, Jiehe S, Yan F, Wei C. Preparation and elevated temperature compressive properties of multiwalled carbon nanotube reinforced Ti composites. Materials Science and Engineering: A. 2010;527:15869.

[22] Baughman RH, Zakhidov AA, De Heer WA. Carbon nanotubes--the route toward applications. science. 2002;297:787-92.

[23] Munir KS, Zheng Y, Zhang D, Lin J, Li Y, Wen C. Microstructure and mechanical properties of carbon nanotubes reinforced titanium matrix composites fabricated via spark plasma sintering. Materials Science and Engineering: A. 2017;688:505-23.

[24] Thostenson ET, Ren Z, Chou T-W. Advances in the science and technology of carbon nanotubes and their composites: a review. Composites Science and Technology. 2001;61:1899-912.

[25] Bakshi S, Lahiri D, Agarwal A. Carbon nanotube reinforced metal matrix composites-a review. International Materials Reviews. 2010;55:41-64.

[26] Tjong SC, Chen H. Nanocrystalline materials and coatings. Materials Science and Engineering: R: Reports. 2004;45:1-88.

[27] Feng X, Sui J, Cai W. Processing of multi-walled carbon nanotube-reinforced TiNi composites by hot pressed sintering. Journal of Composite Materials. 2011;45:1553-7. 
[28] Weston N, Derguti F, Tudball A, Jackson M. Spark plasma sintering of commercial and development titanium alloy powders. Journal of Materials Science. 2015;50:4860-78.

[29] Zhang Z-H, Liu Z-F, Lu J-F, Shen X-B, Wang F-C, Wang Y-D. The sintering mechanism in spark plasma sintering-proof of the occurrence of spark discharge. Scripta materialia. 2014;81:56-9.

[30] Chaim R. Densification mechanisms in spark plasma sintering of nanocrystalline ceramics. Materials Science and Engineering: A. 2007;443:25-32.

[31] Suryanarayana C. Mechanical alloying and milling. Progress in materials science. 2001;46:1-184.

[32] Schoenitz M, Zhu X, Dreizin EL. Carbide formation in Al-Ti mechanical alloys. Scripta Materialia. 2005;53:1095-9.

[33] Feng Y, Zhang H, Hou Y, McNicholas TP, Yuan D, Yang S, et al. Room temperature purification of fewwalled carbon nanotubes with high yield. ACS nano. 2008;2:1634-8.

[34] Delhaes P, Couzi M, Trinquecoste M, Dentzer J, Hamidou H, Vix-Guterl C. A comparison between Raman spectroscopy and surface characterizations of multiwall carbon nanotubes. Carbon. 2006;44:300513.

[35] Datsyuk V, Kalyva M, Papagelis K, Parthenios J, Tasis D, Siokou A, et al. Chemical oxidation of multiwalled carbon nanotubes. Carbon. 2008;46:833-40.

[36] Munir KS, Oldfield DT, Wen C. Role of Process Control Agent in the Synthesis of Multi-Walled Carbon Nanotubes Reinforced Titanium Metal Matrix Powder Mixtures. Advanced Engineering Materials. 2016;18:294-303.

[37] Munir KS, Li Y, Qian M, Wen C. Identifying and understanding the effect of milling energy on the synthesis of carbon nanotubes reinforced titanium metal matrix composites. Carbon. 2016;99:384-97.

[38] Munir KS, Li Y, Liang D, Qian M, Xu W, Wen C. Effect of dispersion method on the deterioration, interfacial interactions and re-agglomeration of carbon nanotubes in titanium metal matrix composites. Materials \& Design. 2015;88:138-48.

[39] Gojny FH, Nastalczyk J, Roslaniec Z, Schulte K. Surface modified multi-walled carbon nanotubes in CNT/epoxy-composites. Chemical physics letters. 2003;370:820-4.

[40] Ye LL, Quan MX. Synthesis of nanocrystalline TiC powders by mechanical alloying. Nanostructured Materials. 1995;5:25-31.

[41] Lohse B, Calka A, Wexler D. Synthesis of TiC by controlled ball milling of titanium and carbon. Journal of materials science. 2007;42:669-75.

[42] Ferrari AC, Robertson J. Interpretation of Raman spectra of disordered and amorphous carbon. Physical review B. 2000;61:14095.

[43] Lespade P, Marchand A, Couzi M, Cruege F. Caracterisation de materiaux carbones par microspectrometrie Raman. Carbon. 1984;22:375-85.

[44] Munir KS, Qian M, Li Y, Oldfield DT, Kingshott P, Zhu DM, et al. Quantitative Analyses of MWCNT-Ti Powder Mixtures using Raman Spectroscopy: The Influence of Milling Parameters on Nanostructural Evolution. Advanced Engineering Materials. 2015;17:1660-9.

[45] Wang F-C, Zhang Z-H, Sun Y-J, Liu Y, Hu Z-Y, Wang H, et al. Rapid and low temperature spark plasma sintering synthesis of novel carbon nanotube reinforced titanium matrix composites. Carbon. 2015;95:396-407.

[46] Machio C, Chikwanda H, Chikosha S. Effect of process control agent (PCA) on the characteristics of mechanically alloyed Ti-Mg powders. Journal of the Southern African Institute of Mining and Metallurgy. 2011;111:149-53.

[47] Esawi A, Morsi K, Sayed A, Taher M, Lanka S. Effect of carbon nanotube (CNT) content on the mechanical properties of CNT-reinforced aluminium composites. Composites Science and Technology. 2010;70:2237-41. 
[48] Kondoh K, Threrujirapapong T, Imai H, Umeda J, Fugetsu B. CNTs/TiC reinforced titanium matrix nanocomposites via powder metallurgy and its microstructural and mechanical properties. Journal of Nanomaterials. 2008;2008:76.

[49] Saheb N, Khalil A, Hakeem A, Al-Aqeeli N, Laoui T, Qutub A. Spark plasma sintering of CNT reinforced Al6061 and Al2124 nanocomposites. submitted to Journal of Composite Materials.

[50] Kondoh K, Threrujirapapong T, Imai H, Umeda J, Fugetsu B. Characteristics of powder metallurgy pure titanium matrix composite reinforced with multi-wall carbon nanotubes. Composites Science and Technology. 2009;69:1077-81.

[51] Kondoh K, Threrujirapapong T, Umeda J, Fugetsu B. High-temperature properties of extruded titanium composites fabricated from carbon nanotubes coated titanium powder by spark plasma sintering and hot extrusion. Composites Science and Technology. 2012;72:1291-7.

\section{FIGURE CAPTIONS}

Fig. 1. SEM morphologies of starting powders: (a) Ti6Al4V, (b) highly entangled MWCNTs, and (c) TEM image of entangled MWCNTs.

Fig. 2. Morphology and evolution of $\mathrm{MWCNT}_{\mathrm{Gr}}$ (a) $\mathrm{SEM}$ image of $\mathrm{MWCNT}_{\mathrm{Gr}}$, (b) Raman spectra of (i) as-received MWCNT and (ii) MWCNT $_{\mathrm{Gr}}$.

Fig. 3. SEM micrographs of admixed $\mathrm{MWCNT}_{\mathrm{Gr}} / \mathrm{Ti} 64$ composite powders with varied wt \% MWCNT $_{G r}$ in the metal matrix (a) $1 \%$ wt MWCNT $_{\mathrm{Gr}}$, (b) $2 \%$ wt $\mathrm{MWCNT}_{\mathrm{Gr}}$, (c) $3 \% \mathrm{wt}$ $\mathrm{MWCNT}_{\mathrm{Gr}}$; (d) - (f) are the corresponding high magnification surface morphologies of the composite powders. 
Fig. 4. XRD patterns of starting and admixed $\mathrm{MWCNT}_{\mathrm{Gr}} / \mathrm{Ti}_{64}$ composite powders (a) $\mathrm{MWCNT}_{\mathrm{Gr}}$, (b) as-received Ti64, (c) Ti64-1\%MWCNT ${ }_{\mathrm{Gr}}$, (d) Ti64-2\%MWCNT $\mathrm{Gr}$ and (e) Ti64-3\%MWCNT $\mathrm{Mr}_{\text {. }}$ Fig. 5. TEM images of $\mathrm{MWCNT}_{\mathrm{Gr}} / \mathrm{Ti64}$ composite powders with varied wt \% $\mathrm{MWCNT}_{\mathrm{Gr}}$ : (a) (c) Ti64-1\%MWCNT ${ }_{\text {Gr, }}$ (d) - (f) Ti64-2\%MWCNT $\mathrm{Gr}$, (g) - (i) Ti64-3\%MWCNT $\mathrm{Gr}$.

Fig. 6. XRD patterns of Ti64 and $\mathrm{MWCNT}_{\mathrm{Gr}} / \mathrm{Ti} 64$ sintered at different temperatures (a) Ti64, (b)

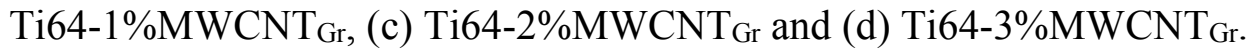

Fig. 7. SEM images of Ti64 and $\mathrm{MWCNT}_{\mathrm{Gr}} / \mathrm{Ti} 64$ composites sintered at 850 and $1000{ }^{\circ} \mathrm{C}$ respectively: (a) as-received Ti64 at $850{ }^{\circ} \mathrm{C}$, (b) as-received Ti64 at $1000{ }^{\circ} \mathrm{C}$, (c) Ti64$1 \% \mathrm{MWCNT}_{\mathrm{Gr}}$ at $850{ }^{\circ} \mathrm{C}$, (d) Ti64-1\%MWCNT $\mathrm{Gr}$ at $1000{ }^{\circ} \mathrm{C}$, (e) $\mathrm{Ti} 64-2 \% \mathrm{MWCNT}_{\mathrm{Gr}}$ at $850{ }^{\circ} \mathrm{C}$, (f) $\mathrm{Ti}_{64-2 \% \mathrm{MWCNT}_{\mathrm{Gr}} 1000{ }^{\circ} \mathrm{C} \text {, (g) Ti64-3\%MWCNT }}$ ar $850{ }^{\circ} \mathrm{C}$ and (h) Ti64-3\%MWCNT $\mathrm{Gr}$ at $1000{ }^{\circ} \mathrm{C}$.

Fig. 8. Raman spectra of starting and $\mathrm{MWCNT}_{\mathrm{Gr}} / \mathrm{Ti} 64$ composite powders (a) as-received Ti64, (b) MWCNT $_{\mathrm{Gr}}$, (c) Ti64-1\%MWCNT $\mathrm{Gr}$ (d) Ti64-2\%:MWCNT $\mathrm{Gr}$, (e) Ti64-3\%MWCNT $\mathrm{Gr}$.

Fig. 9. Raman spectra of unreinforced Ti64 and $\mathrm{MWCNT}_{\mathrm{Gr}} / \mathrm{Ti} 64$ composites sintered at $1000{ }^{\circ} \mathrm{C}$ (a) Ti64, (b) Ti64-1\%MWCNT ${ }_{\text {Gr }}$ (c) Ti64-2\%MWCNT ${ }_{\text {Gr }}$, (d) Ti64-3\%MWCNT Gr.

Fig. 10. Densification patterns in unreinforced Ti64 and $\mathrm{MWCNT}_{\mathrm{Gr}} / \mathrm{Ti}^{6} 4$ composites.

Fig. 11. Microhardness of $\mathrm{MWCNT}_{\mathrm{Gr}} / \mathrm{Ti} 64$ composites with varied weight fractions of $\mathrm{MWCNT}_{\mathrm{Gr}}$ in Ti64 matrix.

Fig. 12. Fractured surfaces of (a) unreinforced Ti64 and $\mathrm{MWCNT}_{\mathrm{Gr}} / \mathrm{Ti} 64$ composites with varied weight fractions of $\mathrm{MWCNT}_{\mathrm{Gr}}$ (b) 1 wt \% $\mathrm{MWCNT}_{\mathrm{Gr}}$, (c) 2 wt \% MWCNT $\mathrm{Gr}$, (d) 3 wt \% MWCNT $_{\mathrm{Gr}},\left(\mathrm{a}^{1}\right)-\left(\mathrm{d}^{1}\right)$ are the corresponding SEM images of $(\mathrm{a})-(\mathrm{d})$ taken at higher magnification respectively. 
FIGURES 

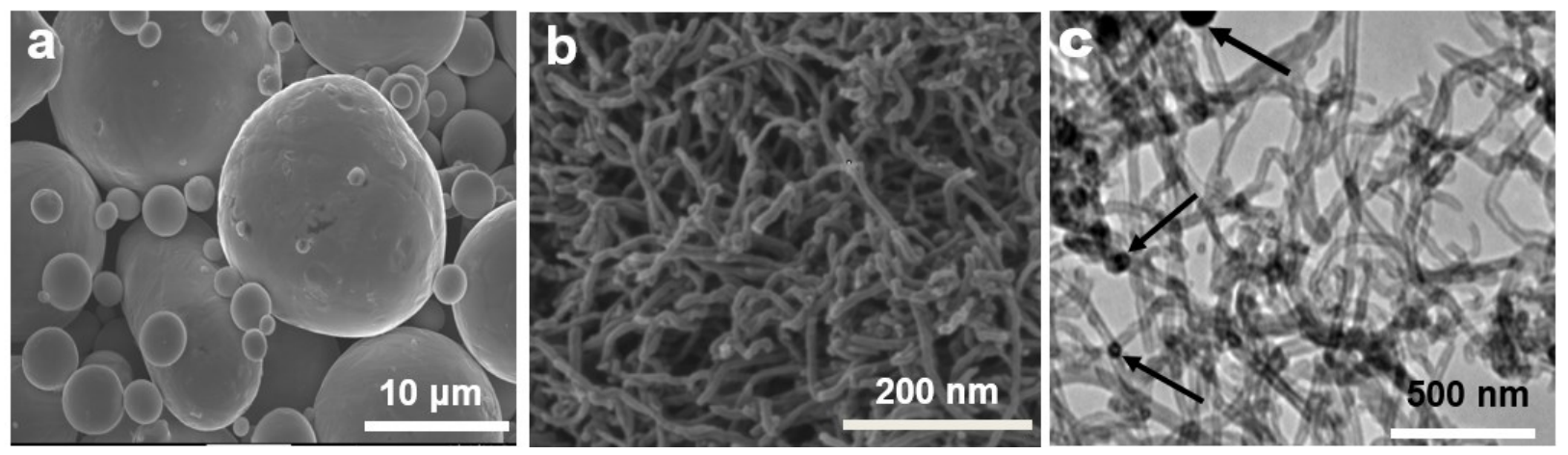

Fig. 1. SEM morphologies of starting powders: (a) Ti6Al4V, (b) highly entangled MWCNTs, and (c) TEM image of entangled MWCNTs. 

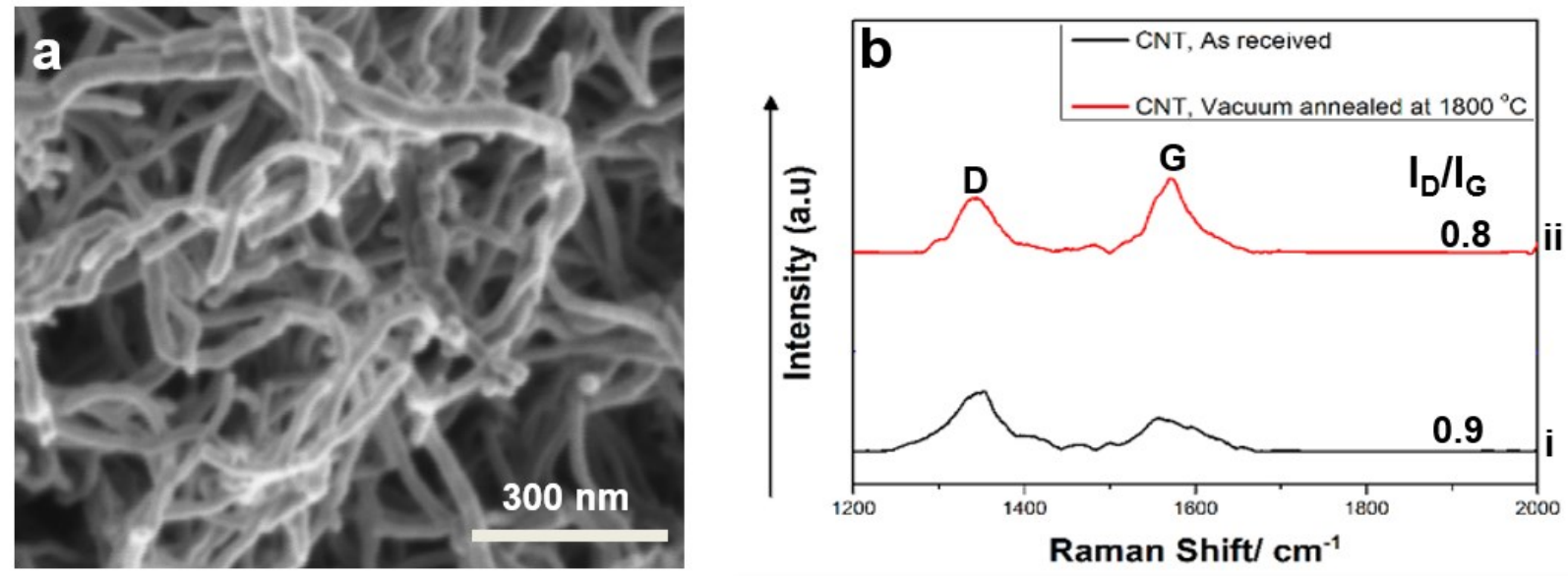

Fig. 2. Morphology and evolution of $\mathrm{MWCNT}_{\mathrm{Gr}}$ (a) SEM image ofMWCNT $\mathrm{Sr}_{\mathrm{G}}$, (b) Raman spectra of (i) as-received MWCNT and (ii) $\mathrm{MWCNT}_{\mathrm{Gr}}$. 

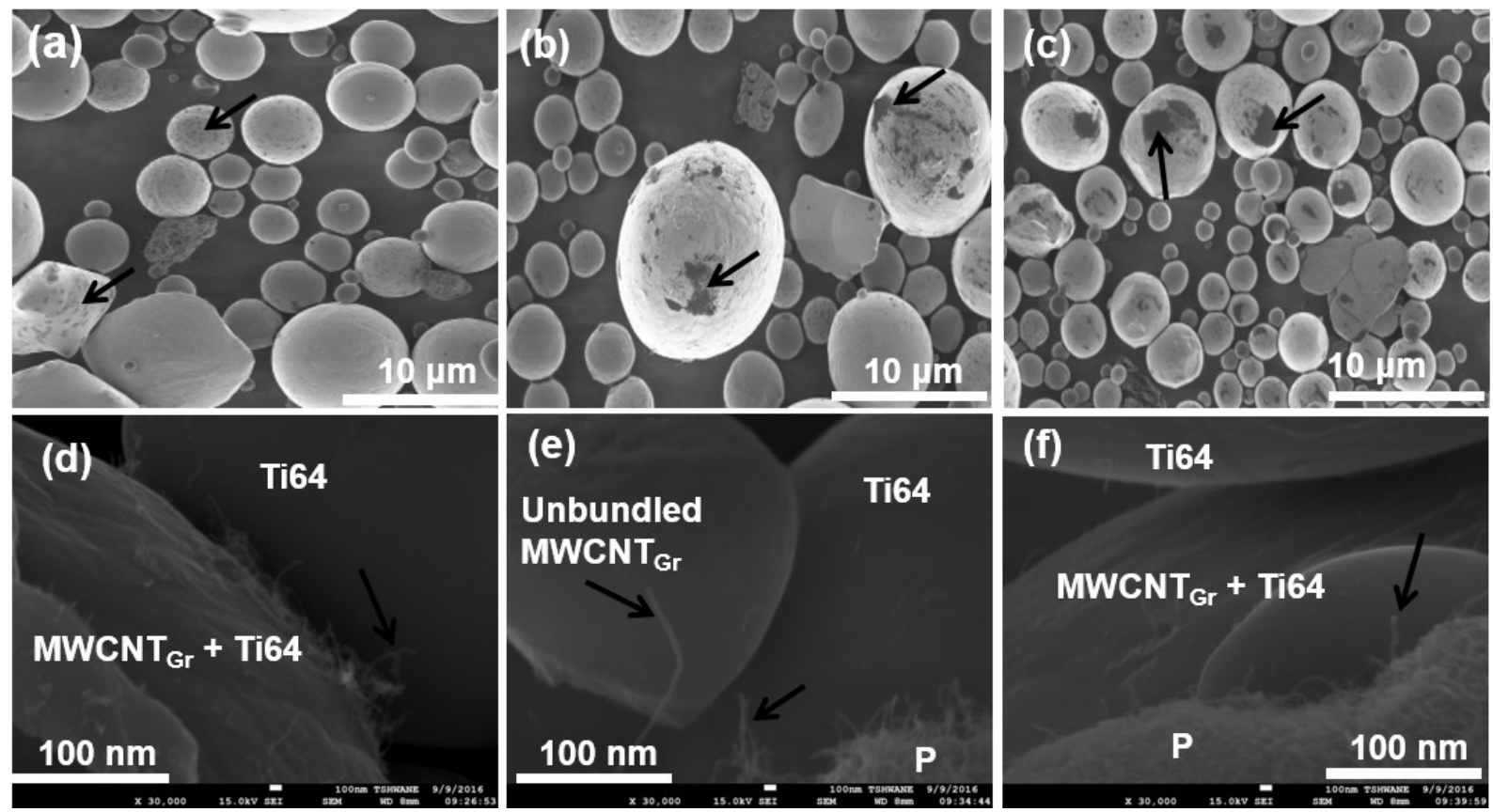

Fig. 3. SEM micrographs of admixed $\mathrm{MWCNT}_{\mathrm{Gr}} / \mathrm{Ti} 4$ composite powders with varied wt $\%$ $\mathrm{MWCNT}_{\mathrm{Gr}}$ in the metal matrix (a) $1 \%$ wt $\mathrm{MWCNT}_{\mathrm{Gr}}$, (b) $2 \%$ wt $\mathrm{MWCNT}_{\mathrm{Gr}}$, (c) $3 \% \mathrm{wt}$ $\operatorname{MWCNT}_{\mathrm{Gr}}$; (d) - (f) are the corresponding high magnification surface morphologies of the composite powders 


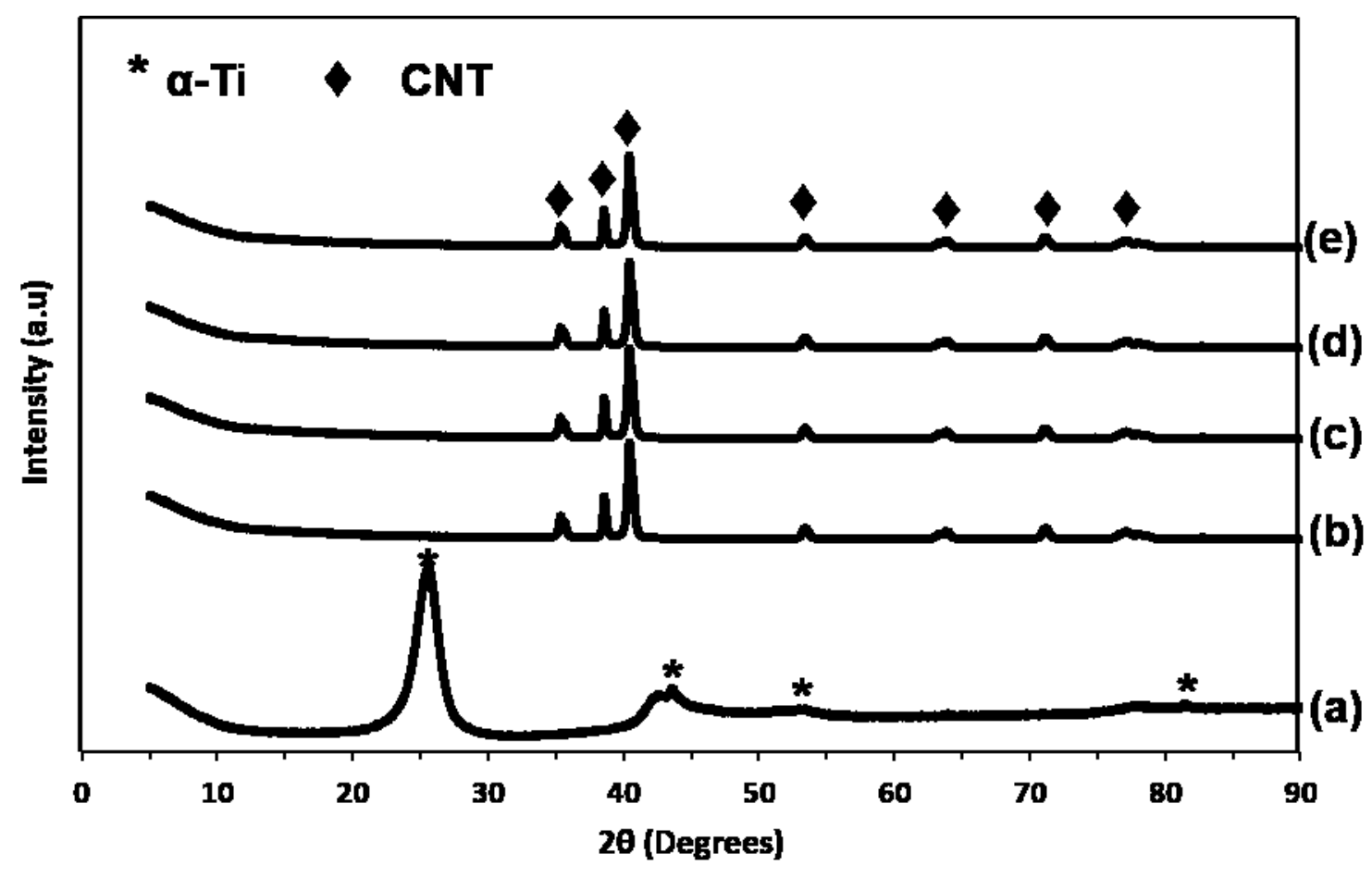

Fig. 4. XRD patterns of starting and admixed $\mathrm{MWCNT}_{\mathrm{Gr}} / \mathrm{Ti} 64$ composite powders (a) $\mathrm{MWCNT}_{\mathrm{Gr}}$, (b) as-received Ti64, (c) Ti64-1\%MWCNT ${ }_{\mathrm{Gr}}$, (d) Ti64-2\%MWCNT $\mathrm{Gr}$ and (e) Ti64-3\%MWCNT $\mathrm{Gr}$. 

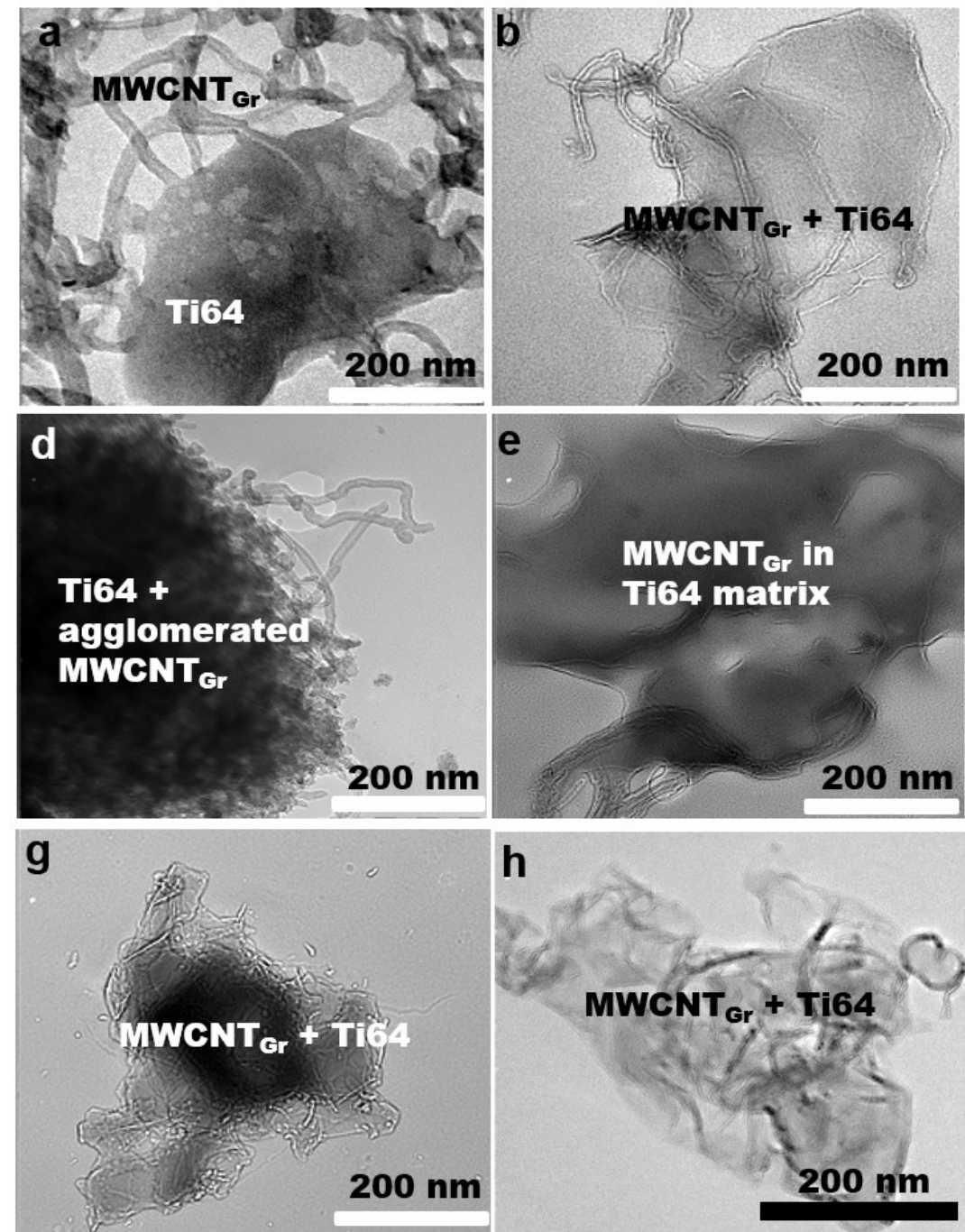
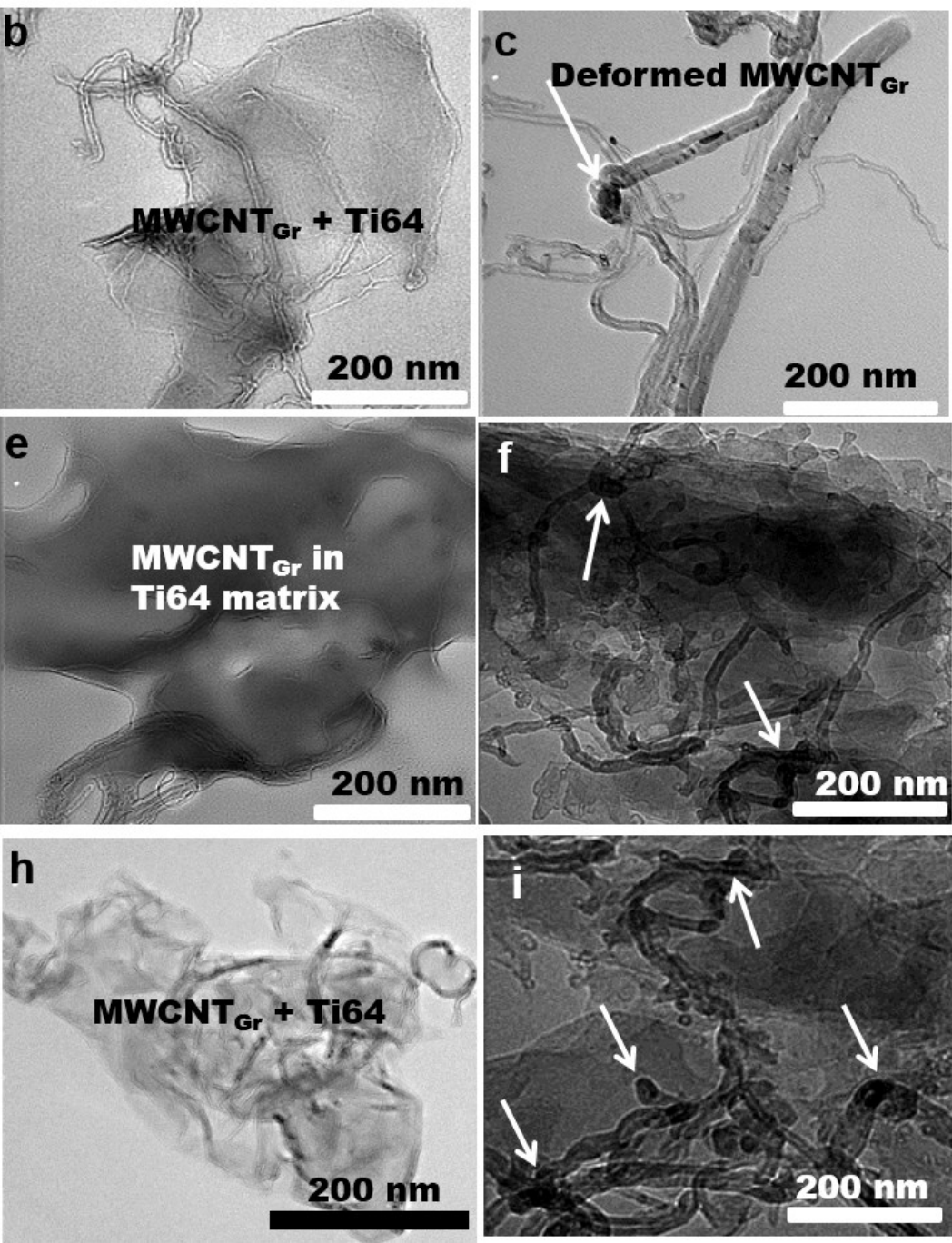

Fig. 5. TEM images of $\mathrm{MWCNT}_{\mathrm{Gr}} / \mathrm{Ti} 4 \mathrm{f}$ composite powders with varied wt $\% \mathrm{MWCNT}_{\mathrm{Gr}}$ : (a) -

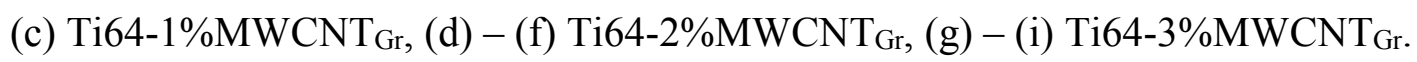




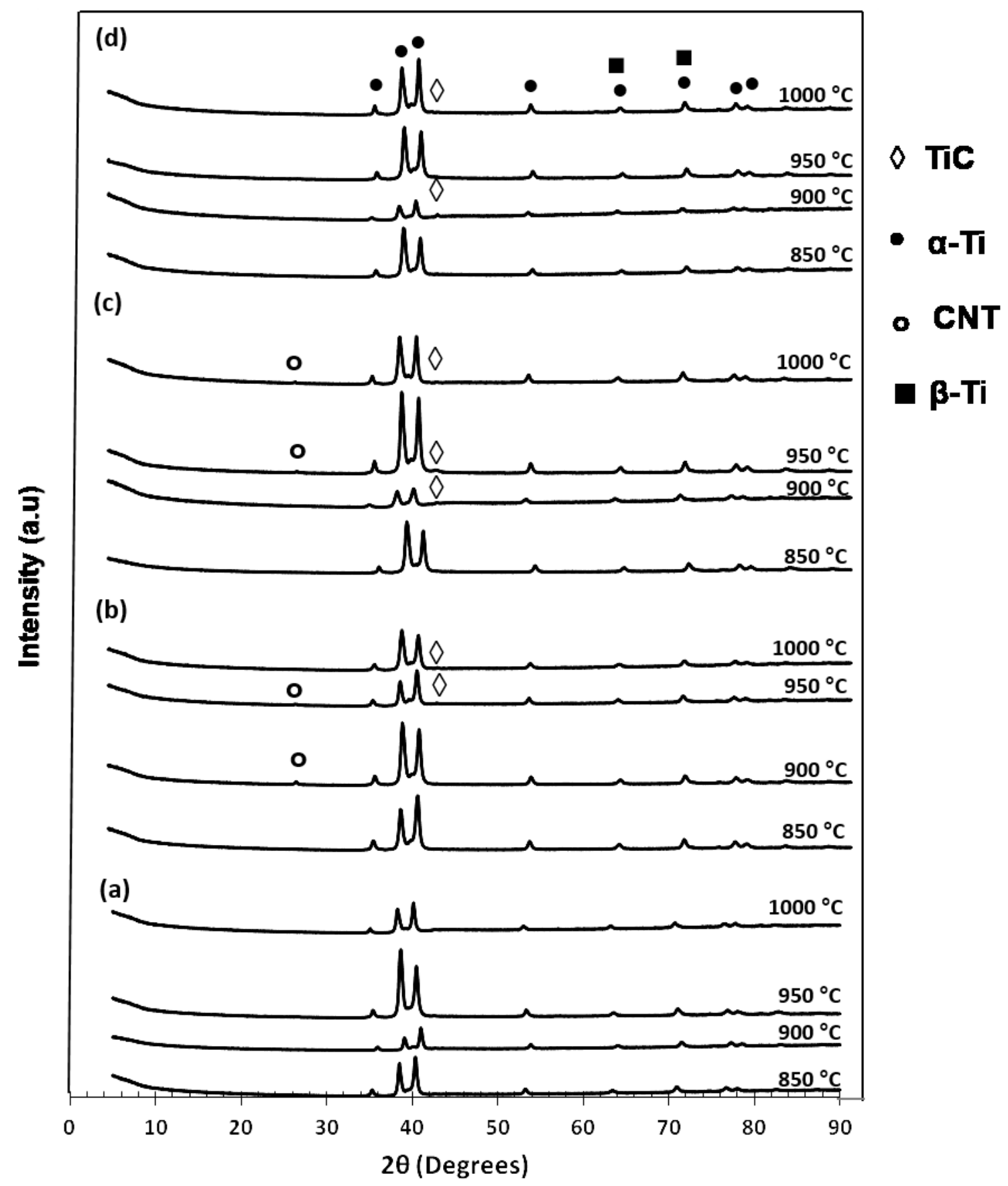

Fig. 6. XRD patterns of Ti64 and MWCNT $\mathrm{Mr}_{\mathrm{Gr}} / \mathrm{Ti} 64$ sintered at different temperatures (a) Ti64, (b) Ti64-1\%MWCNT $_{\mathrm{Gr}}$, (c) Ti64-2\%MWCNT $\mathrm{Gr}$ and (d) Ti64-3\%MWCNT $\mathrm{Mr}_{\text {. }}$ 
T64
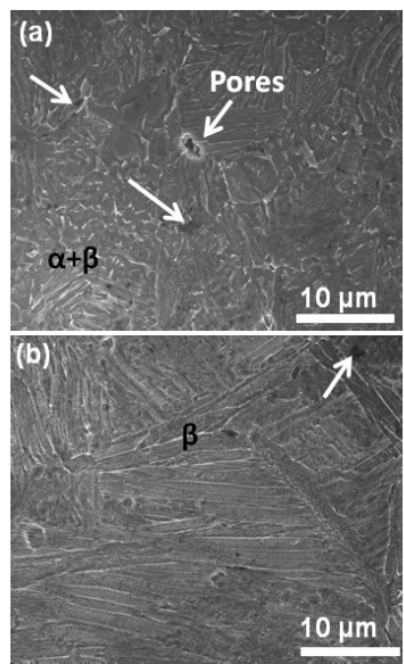

T164-1\%MWCNT $_{\text {Gr }}$

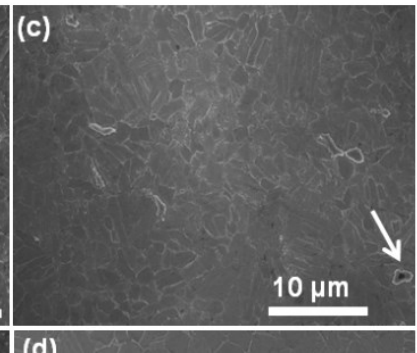

(d)
Ti64-2\%MWCNT

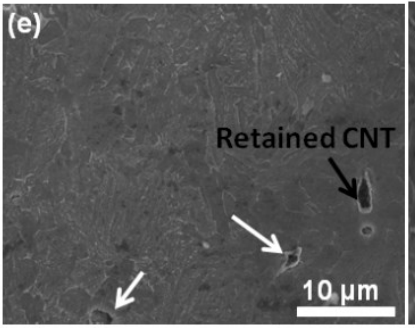

(f)
T64-3\%MWCNT

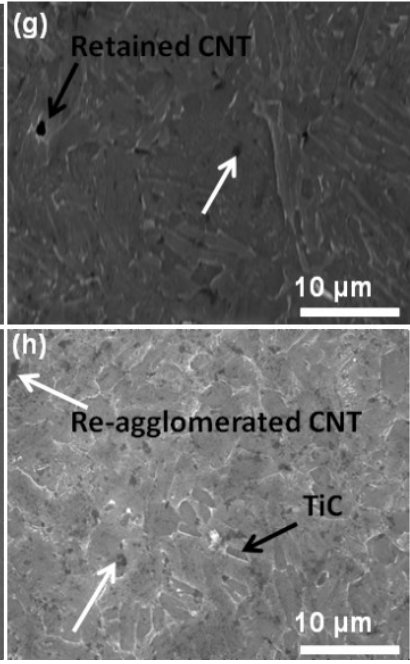

Fig. 7. SEM images of Ti64 and $\mathrm{MWCNT}_{\mathrm{Gr}} / \mathrm{Ti} 64$ compositessintered at 850 and $1000{ }^{\circ} \mathrm{C}$ respectively: (a) as-received Ti64 at $850{ }^{\circ} \mathrm{C}$, (b) as-received Ti64 at $1000{ }^{\circ} \mathrm{C}$, (c) Ti64$1 \% \mathrm{MWCNT}_{\mathrm{Gr}}$ at $850{ }^{\circ} \mathrm{C}$, (d) Ti64-1\%MWCNT $\mathrm{Gr}$ at $1000{ }^{\circ} \mathrm{C}$, (e) $\mathrm{Ti} \mathrm{M}-2 \% \mathrm{MWCNT}_{\mathrm{Gr}}$ at $850{ }^{\circ} \mathrm{C}$, (f) Ti64-2\%MWCNT $\mathrm{Gr} 1000{ }^{\circ} \mathrm{C}$, (g) Ti64-3\%MWCNT Grat $850{ }^{\circ} \mathrm{Cand}(\mathrm{h}) \mathrm{Ti64}-3 \% \mathrm{MWCNT}_{\mathrm{Gr}}$ at $1000{ }^{\circ} \mathrm{C}$. 


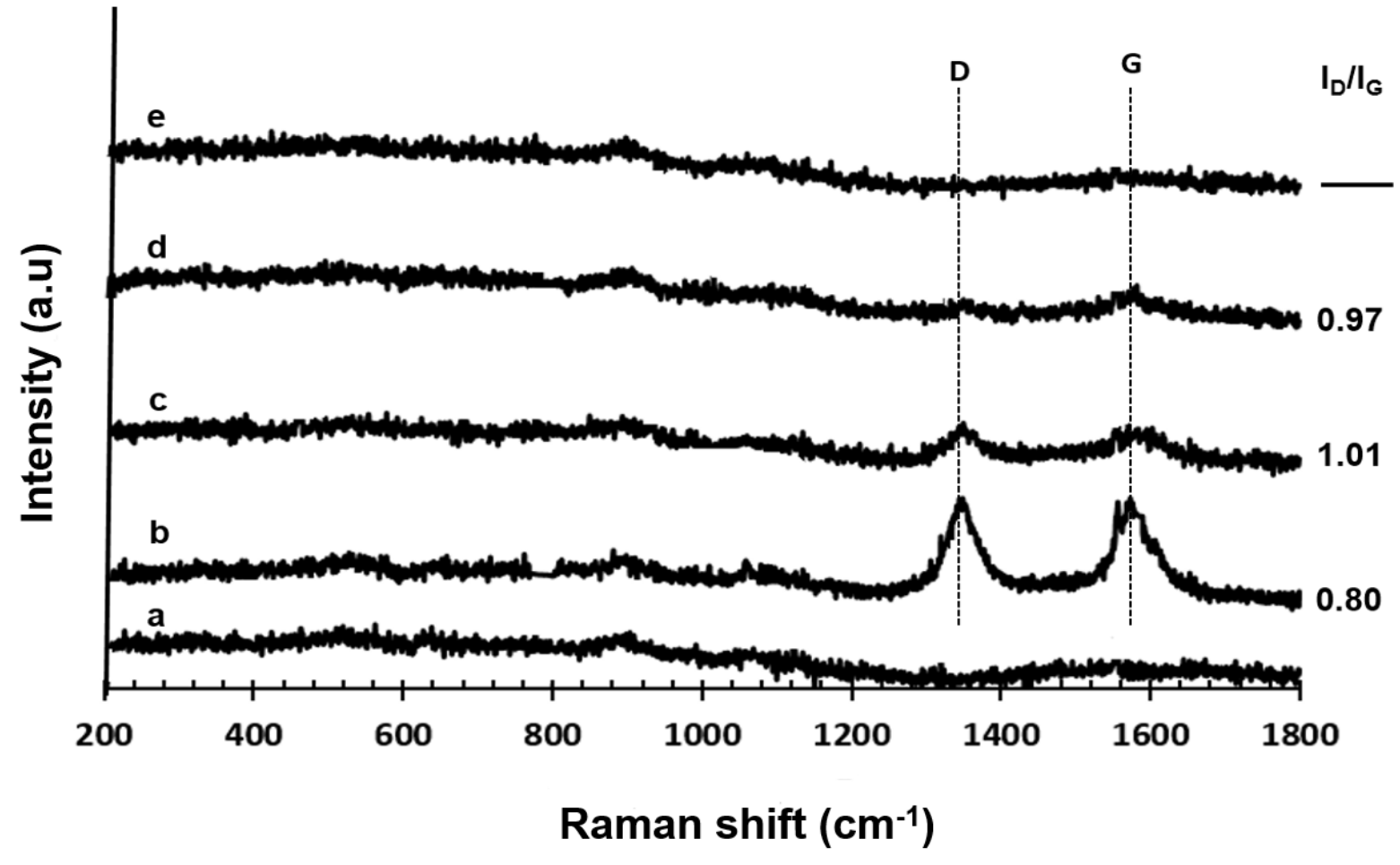

Fig. 8. Raman spectra of starting and $\mathrm{MWCNT}_{\mathrm{Gr}} / \mathrm{Ti} 64$ composite powders (a) as-received Ti64,

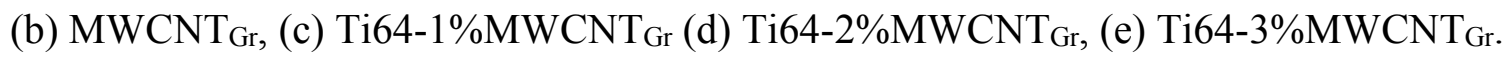




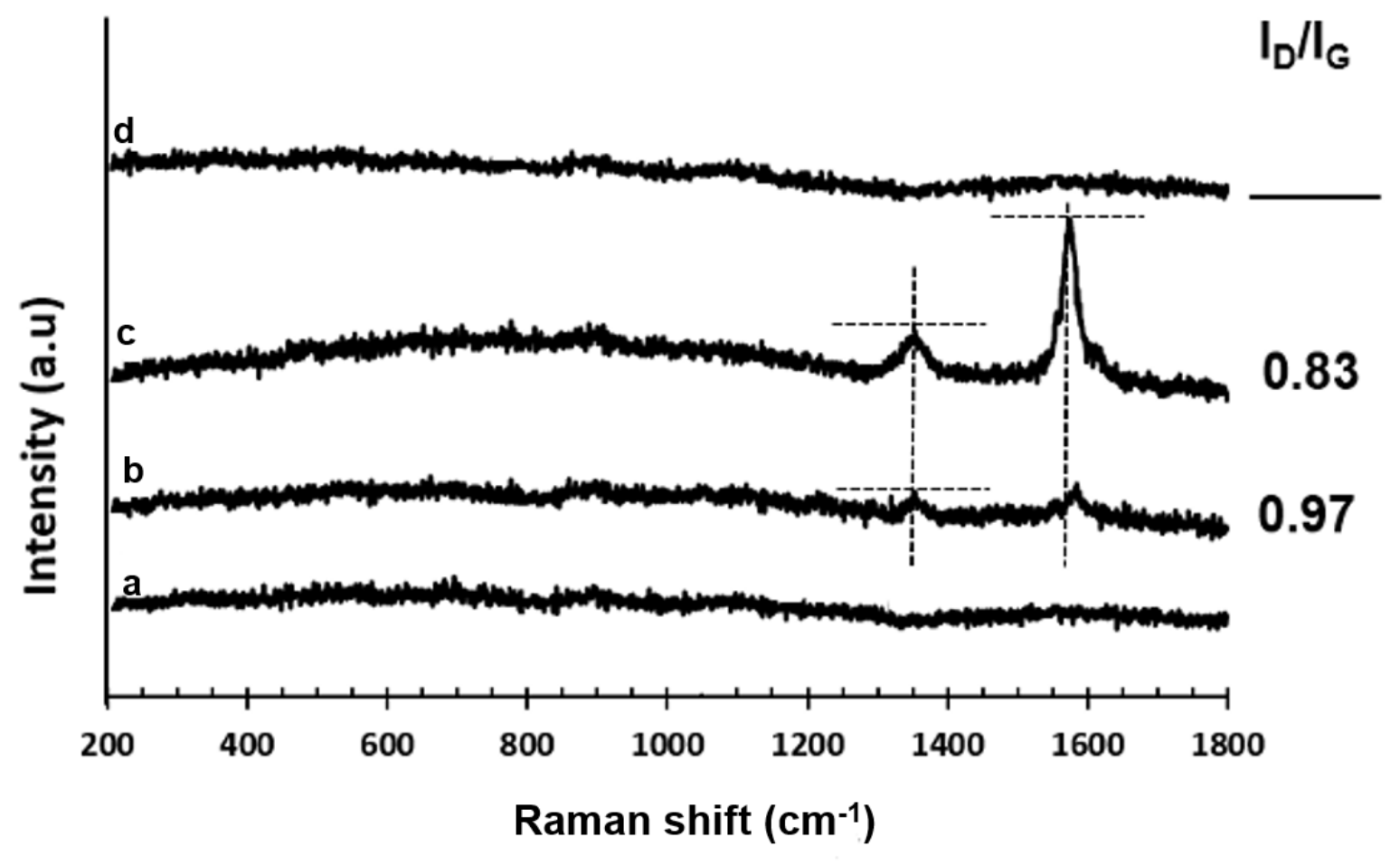

Fig. 9. Raman spectra of unreinforced Ti64and $\mathrm{MWCNT}_{\mathrm{Gr}} / \mathrm{Ti} 64$ composites sintered at $1000{ }^{\circ} \mathrm{C}$ (a) Ti64, (b)Ti64-1\%MWCNT $\mathrm{Gr}$ (c) Ti64-2\%MWCNT $\mathrm{Mr}_{\mathrm{Mr}}$, (d) Ti64-3\%MWCNT $\mathrm{Gr}$. 


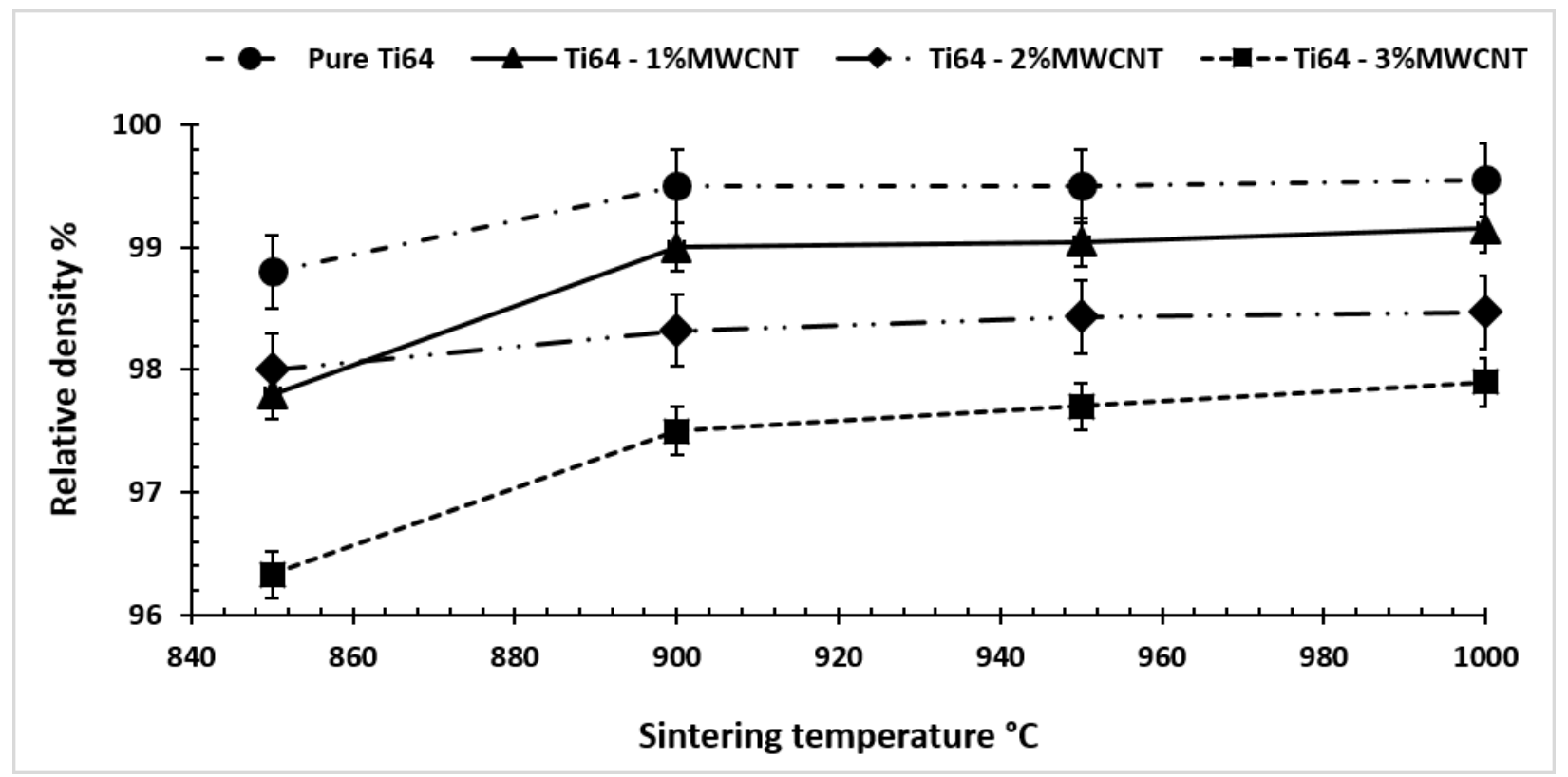

Fig. 10.Densification patterns in unreinforced Ti64 and $\mathrm{MWCNT}_{\mathrm{Gr}} / \mathrm{Ti}^{6} 64$ composites. 


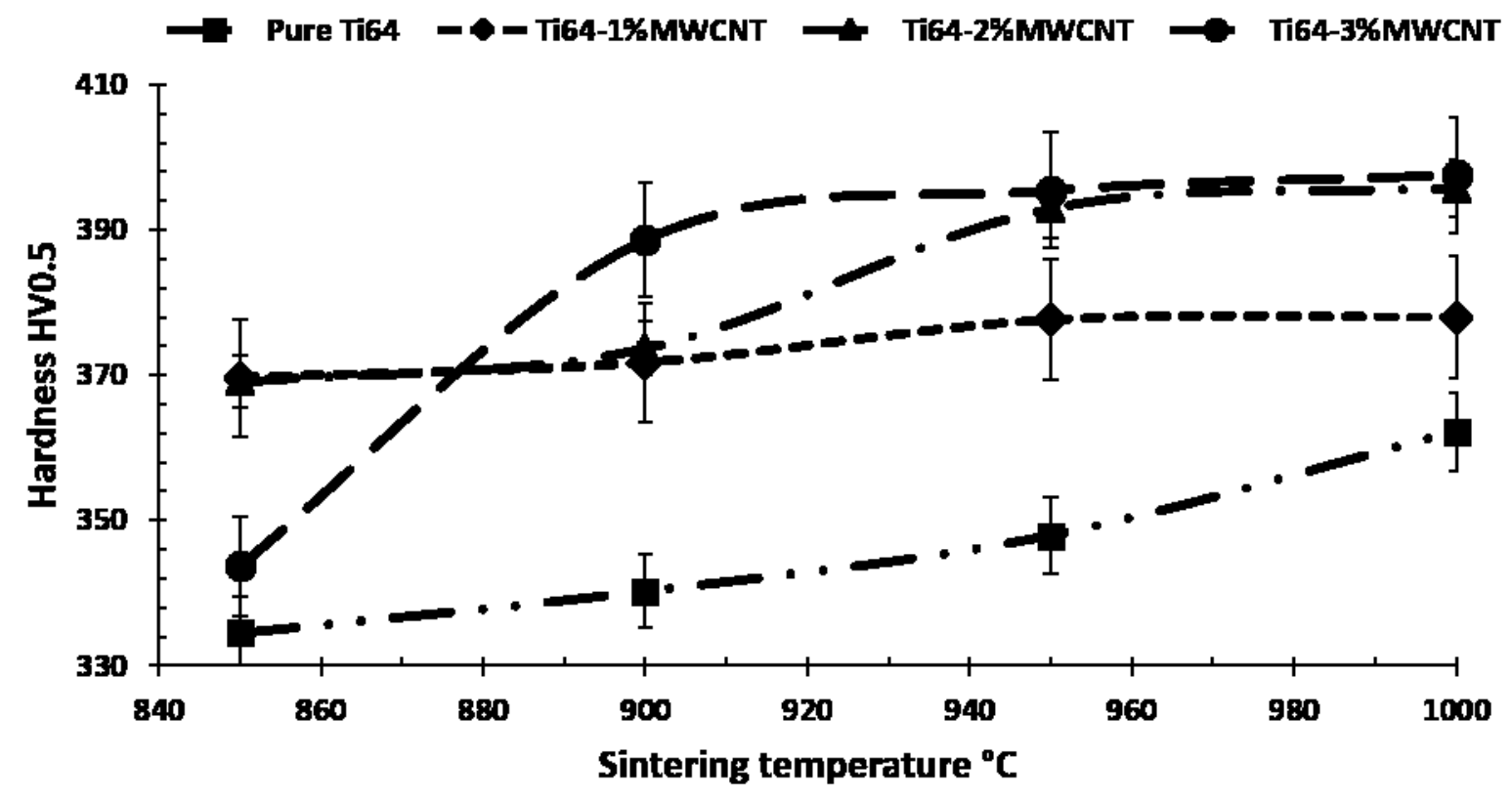

Fig. 11. Microhardness of $\mathrm{MWCNT}_{\mathrm{Gr}} / \mathrm{Ti64}$ composites with varied weight fractions of $\mathrm{MWCNT}_{\mathrm{Gr}}$ in Ti64 matrix. 

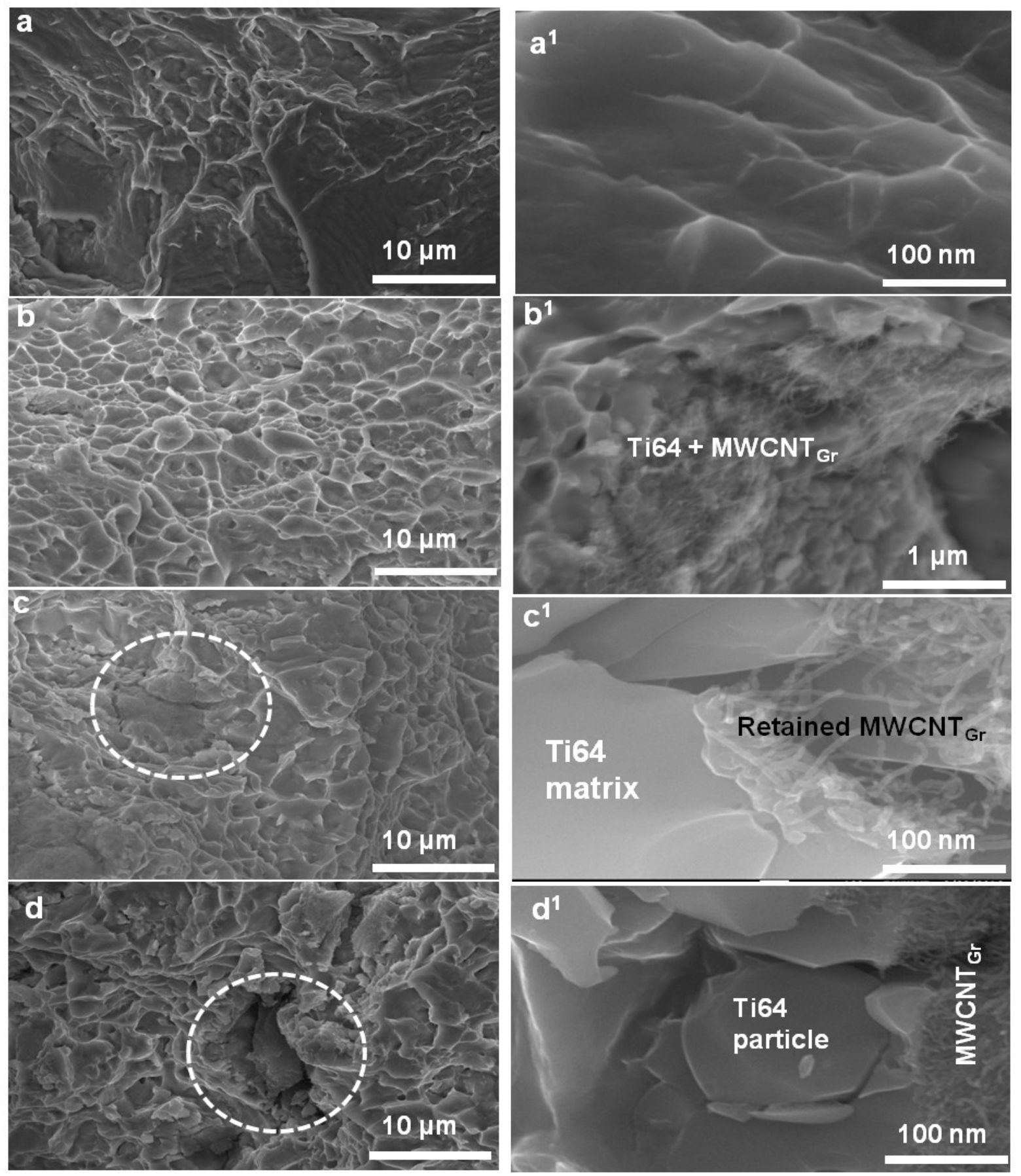

Fig. 12. Fractured surfaces of (a) unreinforced Ti64 and $\mathrm{MWCNT}_{\mathrm{Gr}} / \mathrm{Ti} 64$ composites with varied weight fractions of $\mathrm{MWCNT}_{\mathrm{Gr}}$ (b) 1 wt $\% \mathrm{MWCNT}_{\mathrm{Gr}}$, (c) 2 wt $\% \mathrm{MWCNT}_{\mathrm{Gr}}$ (d) 3 wt \% $\operatorname{MWCNT}_{\mathrm{Gr}},\left(\mathrm{a}^{1}\right)-\left(\mathrm{d}^{1}\right)$ are the corresponding SEM images of (a) - (d) taken at higher magnification respectively. 
